\title{
Research Square \\ Optimization of Strontium Removal Process From Contaminated Water Using Zeolite Nanocomposites
}

\section{Shamal Chandra Karmaker}

Kyushu University: Kyushu Daigaku

\section{Osama Eljamal}

Kyushu University: Kyushu Daigaku

Bidyut Baran Saha ( $\nabla$ saha.baran.bidyut.213@m.kyushu-u.ac.jp )

Kyushu University https://orcid.org/0000-0002-9902-2642

\section{Research Article}

Keywords: adsorption, central composite design, optimization, removal, strontium.

Posted Date: March 19th, 2021

DOI: https://doi.org/10.21203/rs.3.rs-309368/v1

License: (c) (i) This work is licensed under a Creative Commons Attribution 4.0 International License. Read Full License 


\title{
Optimization of Strontium Removal Process from Contaminated Water using Zeolite Nanocomposites
}

\author{
Shamal Chandra Karmaker ${ }^{\text {a, b, c }}$,Osama Eljamal ${ }^{\text {d }}$, Bidyut Baran Saha ${ }^{\text {a, b, * }}$ \\ ${ }^{a}$ Mechanical Engineering Department, Kyushu University, 744 Motooka, Nishi-ku, \\ Fukuoka 819-0395, Japan \\ ${ }^{\mathrm{b}}$ International Institute for Carbon-Neutral Energy Research (WPI-I2CNER), Kyushu \\ University, Japan \\ ${ }^{c}$ Department of Statistics, University of Dhaka, Dhaka-1000, Bangladesh \\ ${ }^{\mathrm{d}}$ Water and Environmental Engineering Laboratory, Department of Earth System Science and \\ Technology, Kyushu University, Japan \\ *Corresponding Author E-mail: saha.baran.bidyut.213@m.kyushu-u.ac.jp
}

ABSTRACT

The effective removal of strontium from polluted water is an emerging issue worldwide, especially in Japan, after the destruction of Fukushima's Daiichi Nuclear Power Plant. In the strontium removal process, statistical optimization of associated factors is needed to reduce the quantity of chemicals and the number of experimental trials. In this study, response surface methodology based on the central composite design was employed for assessing the influence of different factors and their interaction effects on the efficiency of strontium removal. We have considered nanoscale zero-valent iron-zeolite (nZVI-Z) and nano-Fe/Cu zeolite $(\mathrm{nFe} / \mathrm{Cu}-\mathrm{Z})$ as adsorbents for the effective removal of strontium. The present study showed that the most statistically significant potential contributor was initial concentration, followed by contact time in the removal process. The study indicated that the interaction effect between contact time and initial concentration was statistically important, suggesting the need for a multi-mechanism technique in the removal phase of strontium. Tóth, Langmuir, Dubinin-Astakhov (D-A), Freundlich, and Hill isotherm models were also fitted with the experimental strontium adsorption data, in which the Tóth model fitted best compared to the other models based on the RMSD. 
32 Keywords: adsorption; central composite design; optimization; removal; strontium.

$\begin{array}{ll}\text { Abbreviations } & \\ \text { df } & \text { Degrees of freedom } \\ \text { F-value } & \text { Value of F-statistic } \\ \text { MS } & \text { Mean sum of squares } \\ \text { p-value } & \text { Probability value } \\ \text { RMSD } & \text { Root-mean-square deviation } \\ \text { R }^{2} \text { (adj) } & \text { Adjusted } \mathrm{R}^{2} \\ \text { std. error } & \text { Standard error of estimates } \\ \text { SS } & \text { Sum of squares } \\ \text { t-value } & \text { Value of t-statistic }\end{array}$

\section{Greek symbols}

$\begin{array}{ll}\alpha & \text { Level of significance (-) } \\ \tau & \text { Mean removal of strontium }\left(\mathrm{mg} \mathrm{g}^{-1}\right) \\ \lambda_{0} & \text { Overall mean }(\mathrm{mg} / \mathrm{g}) \\ \lambda_{\mathrm{i}} & \text { Coefficients of predictor }(-)\end{array}$

\section{Introduction}

The magnitude-9 earthquake in northeastern Japan and hence, tsunami on March 11, 2011, truly smashed the Daiichi Nuclear Power Plant of Fukushima (Shibata et al. 2016). As a result, a significant number of radioactive materials $\left({ }^{90} \mathrm{Sr}\right.$ and $\left.{ }^{137} \mathrm{Cs}\right)$ have been added to groundwater, surrounding soil, seawater, and the surface of the earth (Shibata et al. 2016; Aoyama et al. 2020). Moreover, due to the rapidly growing reliance on nuclear energy, the handling of radioactive waste has become one of the utmost substantial issues in the worldwide management of nuclear waste and the nuclear industry (Hong et al. 2016a). One of the most prevalent dangerous pollutants that badly affect our atmosphere is radioactive strontium $\left({ }^{90} \mathrm{Sr}\right) .{ }^{90} \mathrm{Sr}$ works with a respective half-life of 28.8 years as a beta-gamma emitter (Liu et al. 2014; Hong et al. 2016b). Strontium is commonly used in various manufacturing industries, such as fireworks, ceramics, ferrite magnets, and optical 
as the basis for human tissue and bone cancer, and leukemia. Further, ${ }^{90} \mathrm{Sr}$ is the ultimate cause of damage to humans by genetically affecting seawater organisms (Liu et al. 2014; Hong et al. 2016b).

The removal of strontium from polluted water is therefore of great concern. The most widely available technique of decontamination is ion exchange, adsorption, evaporation, and magnetic assistance (Ambashta and Sillanpää 2010; Faghihian et al. 2013; Lee et al. 2016; Vipin et al. 2016; Ramanayaka et al. 2020). Besides, chemical precipitation techniques are used for the elimination of radioisotopes from wastewaters (Ambashta and Sillanpää 2010). Currently, ion exchange is one of the sophisticated decontamination techniques. Shubair et al. (2019) investigated the removal of strontium by ion exchange technique using two different adsorbents named nZVI-Z and nFe/CuZ. Authors synthesized and characterized considered nanocomposites, allowing contact time, initial concentration, doses, $\mathrm{pH}$, and temperatures as prominent factors. It has been observed that both composites have been effective in removing strontium from the aqueous solution based on adsorption and kinetics properties. El-Kamash (2008) performed a related study to extract strontium (Sr) and cesium (Cs) from polluted water using zeolite A as inorganic ion exchange material. The author found that $\mathrm{S}_{\mathrm{r}}{ }^{2+}$ ions had higher column performance and adsorption capacity compared to $\mathrm{C}_{\mathrm{s}}{ }^{+}$ions. A study directed by using nano-Fe/Cu particles as an adsorbent for cesium removal from contaminated water and found that temperature and $\mathrm{pH}$ were the dynamic factors (Shubair et al. 2018). Nanosized metal oxides (NMOs) provides a high surface area for removing the heavy metal from contaminated water (Hua et al. 2012). Nanocomposites can eliminate $99 \%$ of $\mathrm{Hg} 2+$, up to $10 \%$ and $90 \%$ greater than the removal attained by the zeolite and the parent fly ash, respectively (Tauanov et al. 2018).

However, in the previous studies, one variable at a time technique was applied, including Shubair et al. (2019). The variables assumed independent to examine the single effect for various aspects of the removal method. The independence assumption is not true, and in these circumstances, it is required to take into account numerous effects concomitantly (Echeverría et al. 2005).

For this reason, factorial experimental design is a very convenient technique, as it produces statistical and mathematical models that describe the interactions between the optimized variables (Can and Yildiz 2006; Ponnusami et al. 2007; Saadat and Karimi-Jashni 2011; Geyikçi and Büyükgüngör 2013). In the factorial design, response surface methodology (RSM) is an 
extensively used mathematical and statistical model for conducting experiments and optimize

79 process conditions (Ranic et al. 2014; Wang et al. 2016, 2019; Ghafarzadeh et al. 2017; Mohammed et al. 2017; Yildirim et al. 2018; Bahrami et al. 2019; Shahnaz et al. 2020). Furthermore, RSM gives a vast amount of information for reducing the number of the experimental trial, the quantity of chemicals, the time, and overall research cost. For instance, magnesium-rich tricalcium aluminate was employed to remove ammonium and phosphorus from wastewater, and the optimal removal process is identified using the response surface methodology (Mao et al. 2021). This study suggested that the removal significantly depends on temperature, dosage, initial concentration, and $\mathrm{pH}$. Moreover, the statistical factorial experimental design was an effective method applied by various researchers in several scientific studies to optimize the heavy metal removal from polluted water using different types of adsorbents (Seki et al. 2006; Geyikçi and Büyükgüngör 2013; Rêgo et al. 2013; Dong and Sartaj 2016; Ghaedi et al. 2018; Jaria et al. 2019; Perez Mora et al. 2019; Maamoun et al. 2020; Rahman et al. 2020a, b). Moreover, response surface methodology was applied to optimize the removal condition and mechanism of $\mathrm{Cr}$ (VI) by $\mathrm{Na} 2 \mathrm{SO} 3 / \mathrm{CaO}$ (Zhao et al. 2017). Besides, it has been shown that the response surface method is used to examine the potential of $\mathrm{Fe} 3 \mathrm{O} 4 /$ mordenite zeolite for the purification of oily wastewater and observed that $\mathrm{pH}$ is the most important factor influencing Chemical Oxygen Demand (COD) and Biochemical Oxygen Demand (BOD) removal (Hesas et al. 2019).

To attain the optimal level of strontium removal from polluted water, the literature and context of this study suggest that the statistical factorial experimental technique be an underlying instrument for identifying the essential factors and their interactions. That is why the response surface methodology is necessary for optimizing strontium removal. RSM was first used in the current study to explore the interaction / combined impact of the various key factors on the efficacy of strontium removals, such as initial concentration, contact time, and $\mathrm{pH}$, and to identify optimal conditions using iron-based nanoparticles-zeolite. Normal probability plot, contour graph, surface plot, and main and interaction effect graph have been constructed, and nonlinear regression analysis and analysis of variances have been conducted for finding significant factors of strontium removal. Assumptions validation of the response surface methodology has been performed by making the residual versus fit and normal probability plots. In the existing literature, only Langmuir and Freundlich models are available. In the present study, we have considered five 
108

$$
4 \mathrm{Fe}^{3+}+3 \mathrm{BH}_{4}^{-}+9 \mathrm{H}_{2} \mathrm{O} \rightarrow 4 \mathrm{Fe}^{0}+3 \mathrm{H}_{2} \mathrm{BO}_{3}^{-}+12 \mathrm{H}^{+}+6 \mathrm{H}_{2}
$$

131

$$
\underbrace{\mathrm{FeCl}_{3}+\mathrm{CuCl}_{2}+\mathrm{Z}}_{\text {1st solution }}+\underbrace{\mathrm{NaBH}_{4}}_{\text {2nd solution }} \rightarrow \mathrm{nFe} / \mathrm{Cu}-\mathrm{Z}
$$


133 The solid products were separated from the aqueous process by centrifugation at $3500 \mathrm{rpm}$ for 60 134 minutes and then consecutively cleaned with deoxygenated deionized to eliminate remaining salts. 135 Similarly, the $n F e / C u-Z$ composite was made as mentioned above and following the equation 3.

\subsection{Characterization of adsorbents}

138 The crystalline structure of the nanocomposites was investigated by X-ray diffraction (XRD) 139 applying $\mathrm{Cu} \mathrm{K \alpha}$ radiation at $0.15418 \mathrm{~nm}$ with a tube voltage of $40 \mathrm{kV}$ and a current of $40 \mathrm{~mA}$. All data were taken within the range of scanning speed of $\min ^{-1}$.

\subsection{Strontium $\left(\mathrm{Sr}^{2+}\right)$ adsorption experiments}

143 Adsorption experimentations were performed at $298 \mathrm{~K}$ through batch technique. The adsorption 144 capabilities of both nanocomposites for $\mathrm{Sr}^{2+}$ were investigated through aqueous solutions of this metal. The standard solutions of $\mathrm{Sr}^{2+}$ were formed in deoxygenated deionized water by dissolving $146 \mathrm{SrCl}_{2} \cdot 6 \mathrm{H}_{2} \mathrm{O}$. $0.2 \mathrm{~g}$ of nanocomposite was added into $100 \mathrm{~mL}$ of $100 \mathrm{mgL}^{-1}$ initial $\mathrm{Sr}^{2+}$ 147 concentration into a conical flask, and several identical conical flasks were prepared for the 148 experimental measurements. The mixture was then wrapped and keep on a stirrer with magnets 149 (RSH-6DN, As One Corporation, Japan) with a rotation speed of $1000 \mathrm{rpm}$. In these experiments, 150 the primary $\mathrm{pH}$ level of the solution was kept at close to 6 . The supernatants were filtered by a 0.2 $151 \mu \mathrm{m}$ PVDF syringe filter after the solutions were stimulated for $1 \mathrm{~h}$ to reach equilibrium. The 152 concentration of $\mathrm{Sr}^{2+}$ was determined by inductively combined plasma mass analysis in the filtrate 153 (ICPM-8500, Shimadzu Corporation, Japan). The impact of $\mathrm{pH}$ on the $\mathrm{Sr}^{2+}$ adsorption ability was 154 investigated at different initial $\mathrm{pH}$ within the given range of 3 and 12. The adjustment of $\mathrm{pH}$ was 155 managed by using volumes of $0.01-1.0 \mathrm{M} \mathrm{HCl}$ or $\mathrm{NaOH}$. To identify the influence of dosage, experiments were conducted with different dosages of prepared nanocomposites ranging from 1 to $10 \mathrm{gL}^{-1}$. The experiments were also performed at various temperatures such as $298,313,328$, and $343 \mathrm{~K}$ for thermodynamic aspects. The kinetic of $\mathrm{Sr}^{2+}$ adsorption on both the nanocomposites was investigated at various initial $\mathrm{Sr}^{2+}$ concentrations such as 1, 5, 50, 100, 150, and $200 \mathrm{mg} / \mathrm{L}$. The concentration of $\mathrm{Sr}^{2+}$ was determined for the different time periods ranging from 5 min to 60 min. To measure the equilibrium adsorption isotherm, experiments were conducted with an initial concentration of $\mathrm{Sr}^{2+}$ in the given range of $1-1000 \mathrm{mgL}^{-1}$. All measurements were replicated three times, and the average value was taken into account for analysis. 
$164 \mathrm{The}^{2+}$ adsorption capability was measured by applying the following equation:

$$
q_{e}=\left(C_{\text {initial }}-C_{\text {equilibrium }}\right) \times(V / m)
$$

166 The coefficient of distribution was measured by considering the following equation:

$$
K_{d}=\left(C_{\text {initial }}-C_{\text {equilibrium }}\right) / C_{\text {equilibrium }} \times(V / m)
$$

Where $q_{e}\left(\mathrm{mgg}^{-1}\right)$ represents the quantity of $\mathrm{Sr}^{2+}$ ions adsorbed, $C_{\text {initial }}\left(\mathrm{mgL}^{-1}\right)$ and $C_{\text {equilibrium }}\left(\mathrm{mgL}^{-}\right.$

${ }^{1}$ ) denote the initial and equilibrium concentration of $\mathrm{Sr}^{2+}$, respectively; $\mathrm{V}$ (L) represents the volume of the aqueous solution, and $\mathrm{m}(\mathrm{g})$ denotes the amount of composites.

\subsection{Response surface methodology}

173 Response surface methodology (Bingöl 2011; Kumari and Gupta 2019; Abdulgader et al. 174 2020) is used to recognize the optimum combination of the factors and their interactions with 175 minimum effort, which is not possible in the traditional statistical analysis. Levels for different 176 factors are assigned in Table 1. The value of high and low levels is considered according to some primary experiments.

Table 1. Factors with notations and levels in response surface methodology.

\begin{tabular}{|l|c|c|c|c|}
\hline \multirow{2}{*}{ Factors (units) } & \multirow{2}{|c|}{$\begin{array}{c}\text { Notation } \\
\text { of factors }\end{array}$} & $\mathbf{- 1}$ & $\mathbf{0}$ & $\mathbf{1}$ \\
\cline { 3 - 5 } & PH (-) & 6 & 9 & 12 \\
Contact time (min) & $\mathrm{B}$ & 5 & 17.5 & 30 \\
Initial concentration $\left(\mathbf{m g L}^{-\mathbf{1}}\right)$ & $\mathrm{C}$ & 100 & 150 & 200 \\
\hline
\end{tabular}

179

180

181

183

184

Besides, it generates mathematical models and some critical plots. A few numbers of experiments are used to discover a lot of information. If nonlinear relation exists, then a polynomial function containing quadratic terms is required, which is executed in this analysis. In this analysis, response surface methodology based on the central composite design is used. Second-order polynomial model using response surface methodology is given in the following equations-

$$
y=\gamma_{0}+\sum_{i=1}^{k} \gamma_{i} x_{i}+\sum_{i=1}^{k} \gamma_{i i} x_{i}^{2}+\sum_{1 \leq i \leq j}^{k} \gamma_{i j} x_{i} x_{j}+\varepsilon
$$


185 Where y represents the outcome variable, $\gamma_{0}$ denotes constant, $\gamma_{i}$ represents the linear coefficient, $186 \gamma_{i i}$ denotes the quadratic coefficient, $\gamma_{i j}$ represents the interaction coefficient, $x_{i}$ and $x_{j}$ is the 187 coded coefficient, and $\varepsilon$ is the random error term.

188

\subsection{Adsorption isotherm model and error evaluation function}

190 It is imperative to fit the isotherm models to know the maximum adsorption capacity, 191 adsorption behavior, and its mechanism. In this study, five popular isotherm models, such as Tóth, 192 Langmuir, Freundlich, Dubinin-Astakhov (D-A), and Hill, are fitted with experimental results.

\section{$194 \quad$ 2.5.1 Tóth model}

195 In both the low and high concentration areas, the Tóth model describes the adsorption 196 mechanism properly (Pal et al. 2016, 2017). It explains well in many adsorption systems with the 197 adsorbent's sub-monolayer coverage. Tóth model is obtained by adding a heterogeneity parameter $198 t$ in the Langmuir model. The following equations can be used to express it-

$$
\frac{W}{W_{0}}=\frac{b_{0} e^{\frac{Q}{R T}} \cdot C_{e}}{\left(1+\left(b_{0} e^{\frac{Q}{R T}} \cdot C_{e}\right)^{t}\right)^{1 / t}}
$$

199 where, $\mathrm{W}$ is instantaneous removal $\left(\mathrm{mgg}^{-1}\right), \mathrm{W}_{0}$ is maximum removal $\left(\mathrm{mgg}^{-1}\right), \mathrm{C}_{\mathrm{e}}$ denotes 200 equilibrium concentration $\left(\mathrm{mgL}^{-1}\right)$, bo represents equilibrium constant $\left(\mathrm{Lmg}^{-1}\right), Q$ represents 201 isosteric heat $\left(\mathrm{Jmol}^{-1}\right), R$ represents universal constant $\left.\left(\mathrm{Jmol}^{-1} \mathrm{~K}^{-1}\right)\right)$. Parameter $\mathrm{t}$ is meant to explain 202 the system heterogeneity.

\subsubsection{Langmuir model}

205 The monolayer adsorption process is characterized by the Langmuir isotherm model. This 206 model assumes that all energy sites on the adsorbent surface are homogeneous and there is no 207 adsorbent-adsorbate interactions (Pal et al. 2017) and presented as,

$$
\frac{W}{W_{0}}=\frac{K_{L} C_{e}}{1+K_{L} C_{e}}
$$


208 where $W$ is instant removal $\left(\mathrm{mgg}^{-1}\right), W_{0}$ is maximum removal $\left(\mathrm{mgg}^{-1}\right), K_{L}$ indicates Langmuir

209 constant $\left(\mathrm{Lmg}^{-1}\right)$, and $\mathrm{C}_{\mathrm{e}}$ indicates equilibrium concentration $\left(\mathrm{mgL}^{-1}\right)$.

210

$211 \quad 2.5 .3$ Freundlich model

212 Freundlich isotherm is the most basic model that describes reversible and non-ideal adsorption.

213 For understanding the adsorption mechanism, this model is described as follows (Pal et al. 2017).

$$
W=K_{f} C_{e}^{1 / n}
$$

214 where, $W$ is strontium removal $\left(\mathrm{mgg}^{-1}\right), K_{f}$ indicates Freundlich constant $\left(\mathrm{mgg}^{-1}\right)\left(\mathrm{mgL}^{-1}\right)^{-(1 / \mathrm{n})}$, and

$215 n$ represent the heterogeneity constant. Henry's law is a special case of the Freundlich isotherm 216 model when $n=1$.

217

\subsubsection{Dubinin-Astakhov (D-A) model}

The (D-A) isotherm model (Rocky et al. 2019) is used by the researchers because it can accurately estimate the adsorption quantity for different adsorption pairs. Generally, this model is

221 used for a high degree of the heterogeneous adsorbent. The D-A model is slightly modified for 222 removal application by replacing pressure $(\mathrm{P})$ with equilibrium concentration $\left(\mathrm{C}_{\mathrm{e}}\right)$ and saturation 223 pressure with strontium density $\left(\rho_{c}\right)$. It can be stated as,

$$
\frac{W}{W_{0}}=\exp \left[-\left(\frac{R T}{E} \ln \left(\frac{\rho_{c}}{C_{e}}\right)\right)^{n}\right]
$$

224 Where the parameters $\mathrm{n}$ and $\mathrm{E}$ indicate heterogeneity factor (-) and characteristic energy 225 (Jmole-1), respectively. $\mathrm{R}$ and $\mathrm{T}$ represent the universal constant (Jmole-1K-1)) and $\mathrm{K}$, 226 correspondingly.

\subsubsection{Hill model}

229 In order to explain the attaching of different species to homogeneous substrates, the Hill equation (Rahman et al. 2019) is used. It can be presented as follows- 


$$
\frac{W}{W_{o}}=\frac{\left(\frac{\rho_{c}}{C_{e}}\right)^{n_{H}}}{K_{D}+\left(\frac{\rho_{c}}{C_{e}}\right)^{n_{H}}}
$$

231 Here, $\mathrm{K}_{\mathrm{D}}$ is Hill constant, $\mathrm{n}_{\mathrm{H}}$ indicates binding interaction coefficient, $\mathrm{C}_{\mathrm{e}}$ and $\rho_{c}$ denote 232 equilibrium concentration $\left(\mathrm{mgL}^{-1}\right)$, and strontium density $\left(\mathrm{mgL}^{-1}\right)$.

\subsubsection{Root mean square deviation (RMSD)}

235 Researchers used RMSD frequently to estimate errors between experimental data and a model's expected value (Rahman et al. 2018), which can be stated as,

$$
R M S D=\sqrt{\frac{\sum_{i=1}^{n}\left(W_{\text {experimental }}-W_{\text {calculated }}\right)_{i}^{2}}{N}}
$$

237 In this analysis, a generalized reduced gradient (GRG) nonlinear optimization technique was used

238 to optimize the parameters using the RMSD error function. The RMSD follows the normal 239 distribution, which is the required assumption of the ordinal least square method.

\section{Results and discussion}

242 Response surface methodology was considered to evaluate the importance of the main factors $243 \mathrm{pH}$, contact time ( $\mathrm{min})$, and initial concentration $\left(\mathrm{mgL}^{-1}\right)$, and their interaction effects on strontium 244 removal. The removal of strontium from an aqueous solution is regarded as the outcome variable 245 in this study.

\subsection{Characterization of nanocomposites}

248 Fig. 1(a) shows the XRD pattern of zeolite, which discovered key characteristic $2 \theta$ peaks at $24928.74^{\circ}, 29.35^{\circ}, 29.48^{\circ}, 31.63^{\circ}, 36.60^{\circ}, 36.66^{\circ}, 43.53^{\circ}$ and $47.57^{\circ}$ belonging to $\mathrm{SiO} 2$ and $2 \theta$ peaks 250 at $12.50^{\circ}, 26.18^{\circ}, 29.33^{\circ}, 31.89^{\circ}, 34.53^{\circ}, 34.81^{\circ}$, and $36.62^{\circ}$ correspond to the presence of $\mathrm{Al} 2 \mathrm{O} 3$ 251 (Amen et al. 2017). Fig. 1 (b) and Fig. 1(c) show the XRD pattern diffraction peaks of nZVI and $252 \mathrm{nFe} / \mathrm{Cu}$ at $2 \theta=44.60^{\circ}, 64.68^{\circ}$ and $82.35^{\circ}$, indicating the presence of pure iron metal (Amen et al. 253 2018). Fig. 1(d) and Fig. 1(e) show the XRD pattern of nZVI-Z, and $n F e / C u-Z$ composites, the 254 crystal structure of iron and zeolite changes were detected in their XRD analysis. Following the 
255 iron loading on zeolite, the diffraction peaks displayed a lower intensity compared to pure iron and 256 zeolite. This meant that the crystal structure of zeolite and iron was affected in the period of the 257 synthetic process of the nanocomposites.

(a)

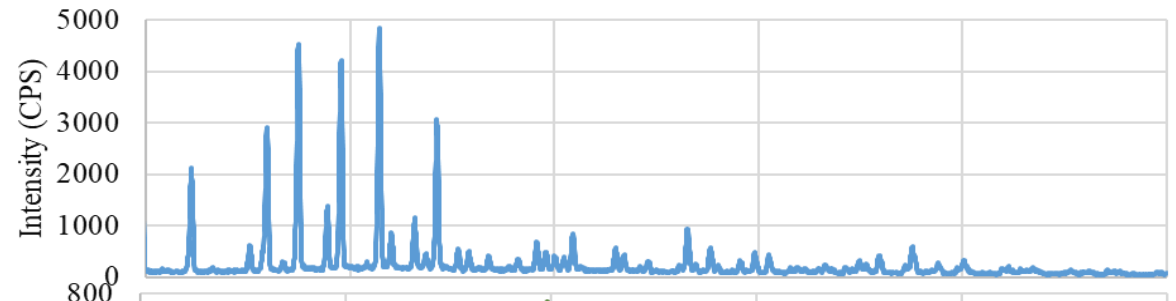

(b)

(c)

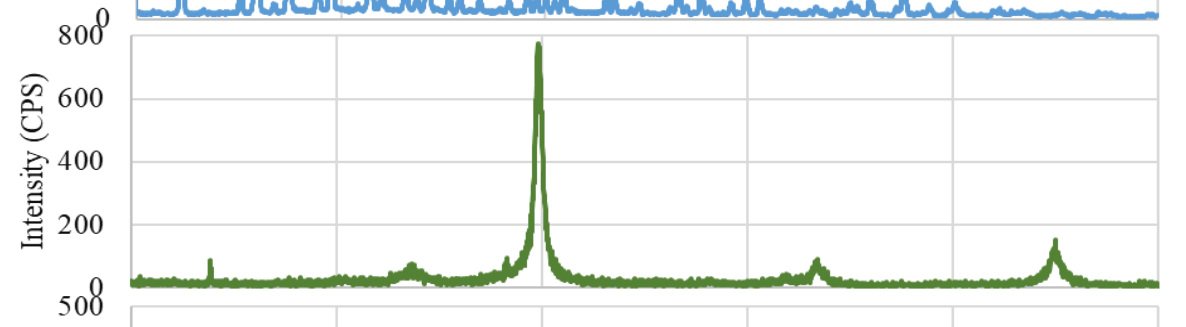

(d)

(e)
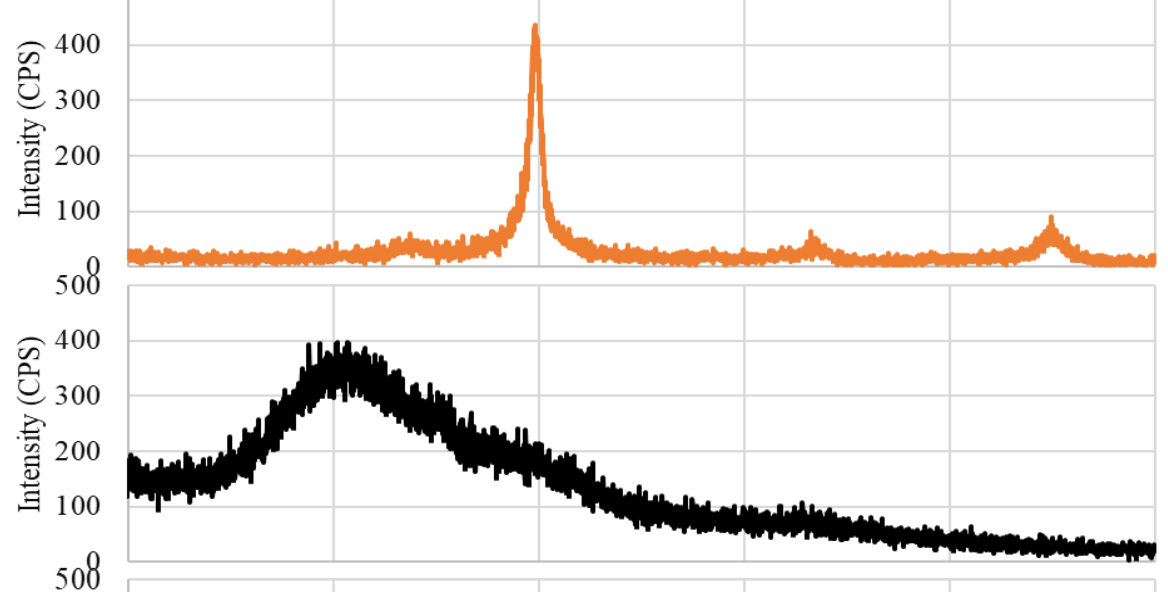

Fig. 1. XRD patterns of (a) zeolite, (b) nZVI, (c) nFe/Cu composite (d) nZVI-Z composite (e) $\mathrm{nFe} / \mathrm{Cu}-\mathrm{Z}$ composite.

\subsection{Normal plot of standardized effect}

263 The normal plot presented below for the strontium removal onto two different adsorbents. It determines the importance, direction, and magnitude of the effects. The plot depicted in Fig. 2 
displays the standardized effects comparative to a distribution fit line for the case when all the effects on strontium removal are zero. The standardized effects are measured based on t-statistic, considering the impact of all factors is zero as a null hypothesis.

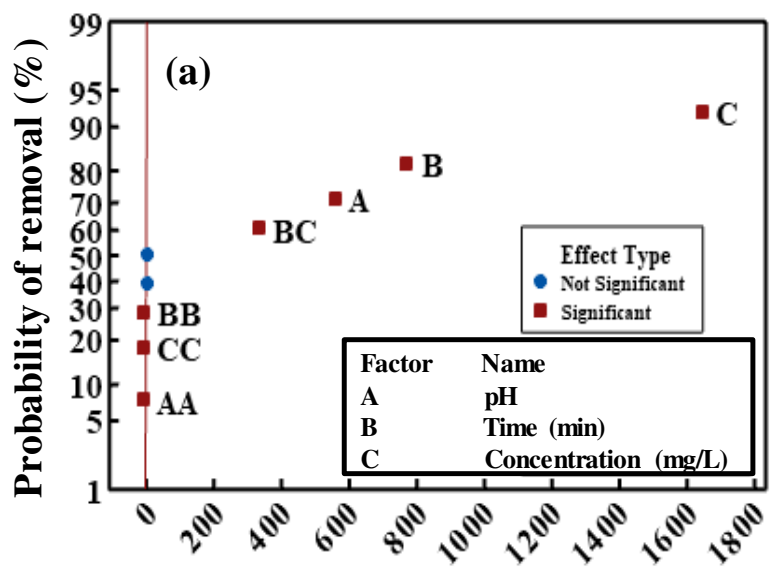

Standardized effect

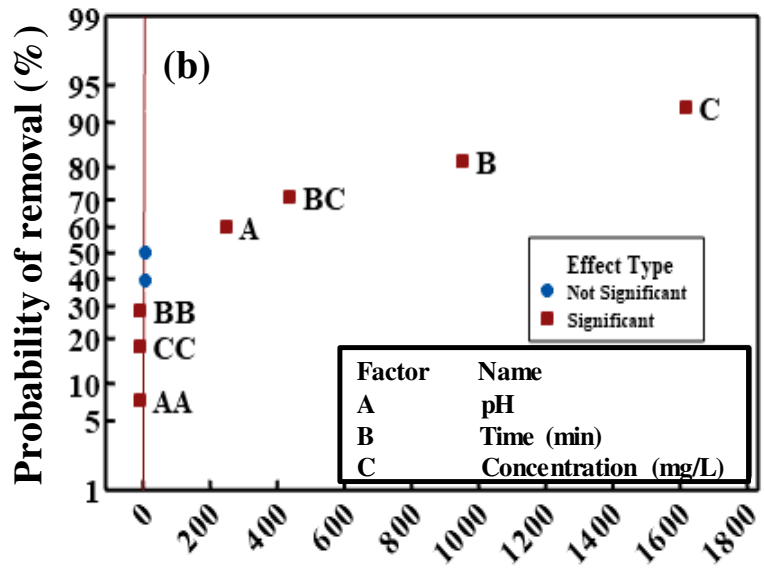

Standardized effect

Fig. 2. Probability graph for (a) nZVI-Z and (b) $n F e / C u-Z$ adsorbent $(\alpha=5 \%)$.

Each point on the plot denotes the effect of factor, and effects which are distant from zero are more potential compared to the adjacent one. Statistically significant and insignificant factors are presented by different colors and shapes of the points. The points placed on the right hand side and left hand side of the zero lines indicate the positive and negative effects on the strontium removal, respectively. It is evident from Fig 2(a) for adsorbent nZVI-Z, that the point indicating initial concentration $(\mathrm{C})$ has the highest chance of statistically significant positive effect on strontium removal followed by contact time (B), $\mathrm{pH}(\mathrm{A})$, and the interaction between contact time and concentration (BC) at 5\% level of significance. This meant that the probability of removal of strontium increases when the process changes from low level to high level of the associated factors.

The quadratic effect of $\mathrm{pH}$, time, and initial concentration, on the other hand, has a statistically significant negative impact on the removal of strontium. Furthermore, only the BC has a significant positive effect, whereas the other two interactions, $\mathrm{AB}$ and $\mathrm{AC}$, are insignificant. Except for the interaction effect BC (contact time and concentration) in Fig. 2(b), similar outcomes are found for the $\mathrm{nFe} / \mathrm{Cu}-\mathrm{Z}$. The effect of $\mathrm{pH}$ is high than the interaction effect $\mathrm{BC}$ for the adsorbent nZVI-Z, whereas the reverse is true for the $\mathrm{nFe} / \mathrm{Cu}-\mathrm{Z}$. 


\subsection{Main and interaction effect}

288 The main and interaction effect plots for every factor in the optimization process were used to understand the mean differences of the output variable of each factor. The main effect plot expressed in Fig. 3(a) illustrates a positive relationship between adsorption of strontium removal and each of the three factors, meaning that removal increases when the factors $(\mathrm{pH}$, contact time, and concentration) level increases from the lower level to the upper level. By comparing the three graphs expressed in Fig. 3(a), it is found that the concentration curve is sharper than other factors, meaning that concentration is a more influential factor than others. Fig. 3(b) represented the interaction effect, as the lines are not parallel for the interaction between contact time and initial concentration $(\mathrm{BC})$ on the removal of strontium. Interaction occurs when one factor produces a different effect on the response (strontium removal) at different levels of another factor. The existence of the interaction effect designates the necessity of a multi mechanism technique for the removal process. The lines are parallel for other interactions $(\mathrm{pH}$ and contact time) and $(\mathrm{pH}$ and concentration), suggesting no interaction effect on the removal process.

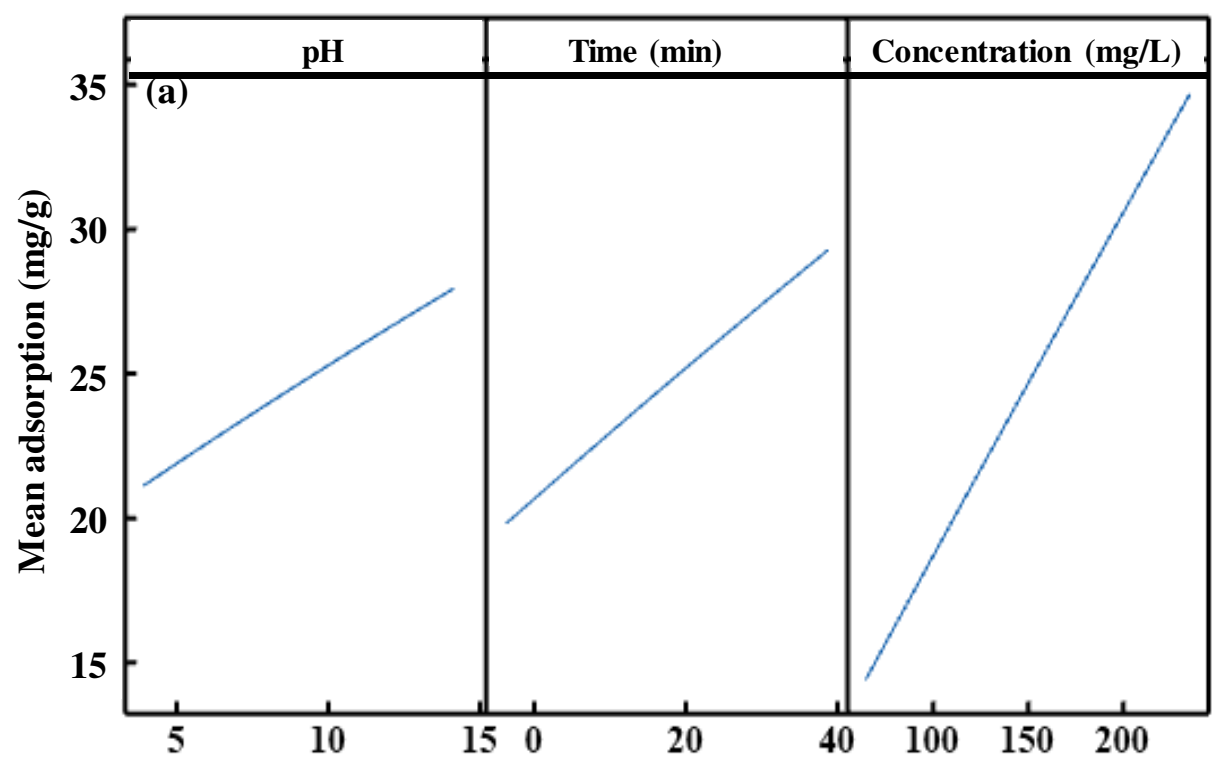

301

302

303

304

305

306 
307

308

309

310

311

312

313

314

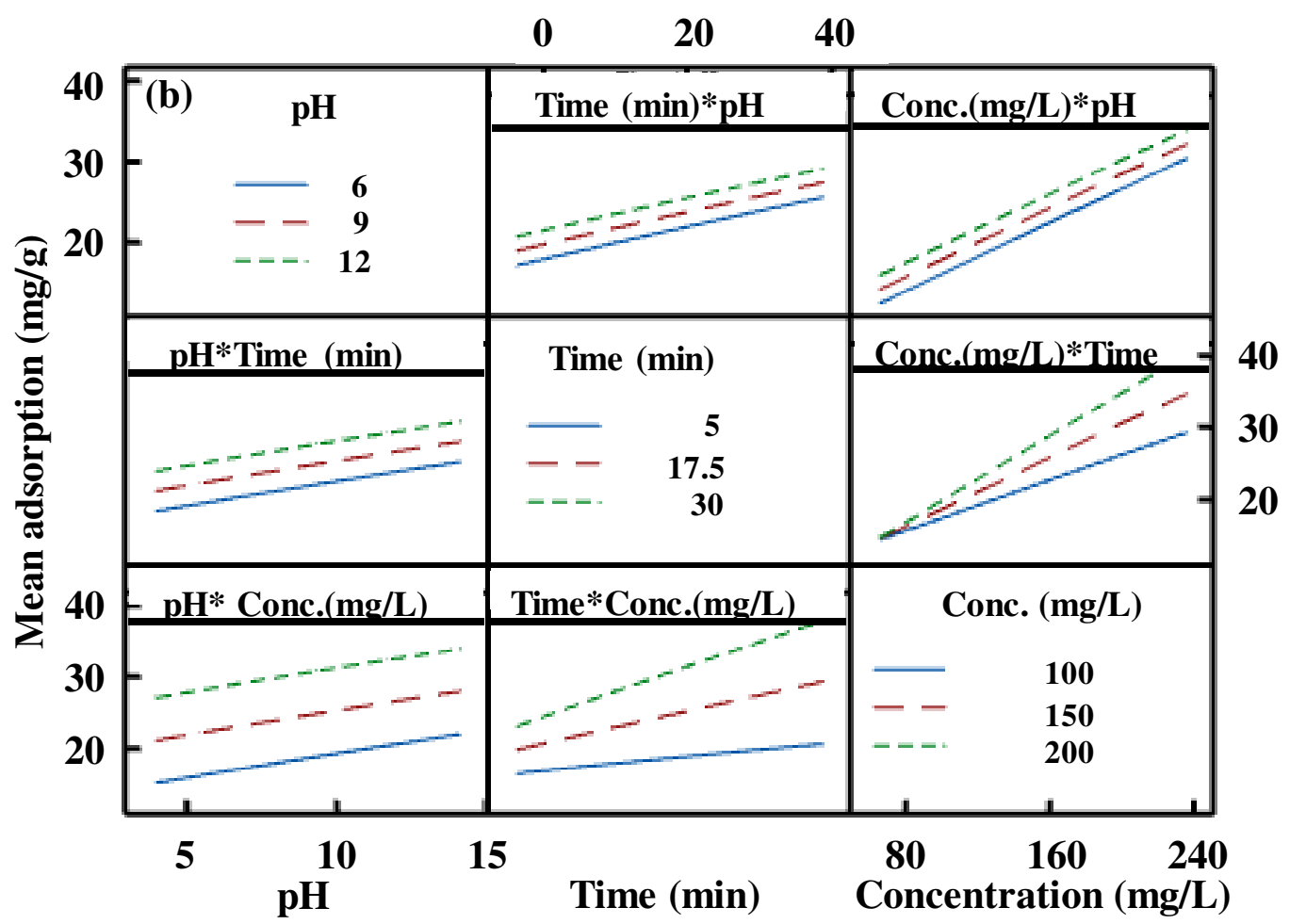

Fig. 3(a). Main and (b) interaction effect graph for the nZVI-Z $(\alpha=5 \%)$.

Similar findings are found for nFe/Cu-Z composite portrayed in Fig. 4(a) and Fig. 4(b).

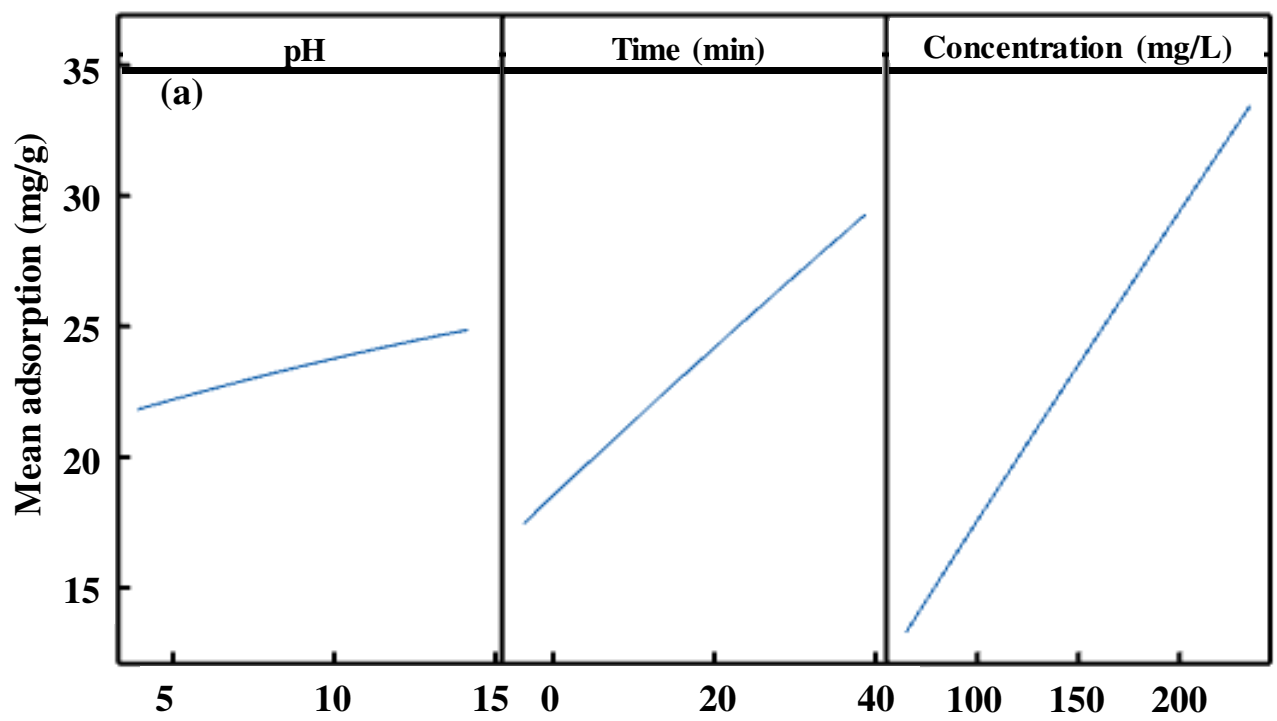




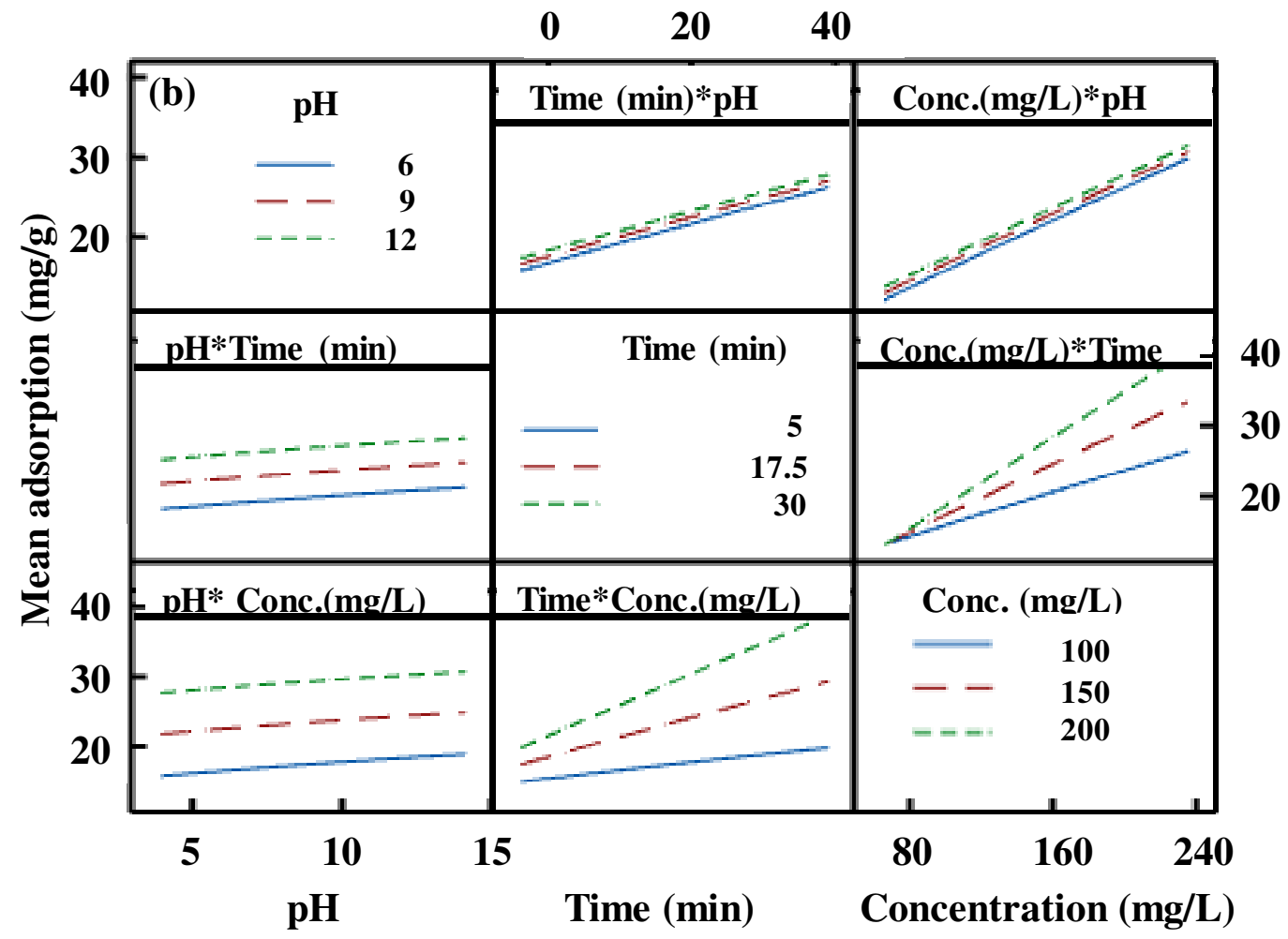

Fig. 4(a). Main and (b) interaction effect graph for the $n F e / C u-Z(\alpha=5 \%)$.

\subsection{Contour plot for the optimum area of strontium removal}

321 The contour plot is used to observe the association between predictor variables and regressed

322 variables. It gives an idea of a two-dimensional view so that all points that have a similar response 323 are related to producing contour lines of constant responses. It comprises three elements, i)

324 predictors on the $\mathrm{x}$-axis and $\mathrm{y}$-axis, ii) contour line that connects points having the same response 325 and, iii) contour bands of the same color indicate ranges of the response variable. The contour plot 326 presented in Fig. 5 illustrates the relationship between factors (contact time, initial concentration, 327 and $\mathrm{pH}$ ) used to remove strontium from wastewater and the amount of strontium removal for 328 adsorbent nZVI-Z. The darker region represents higher removal. This higher removal seems to 329 form the upper right corner of the graph, which is the expected region. On the other hand, the 330 region of the lower left corner of the graph represents the lower removal process, which is not 
331 desirable. Curvature within the contour plot also assures that contact time and initial concentration

332 has interacted. A similar pattern is observed in Fig. 6 for $\mathrm{nFe} / \mathrm{Cu}-\mathrm{Z}$.

333
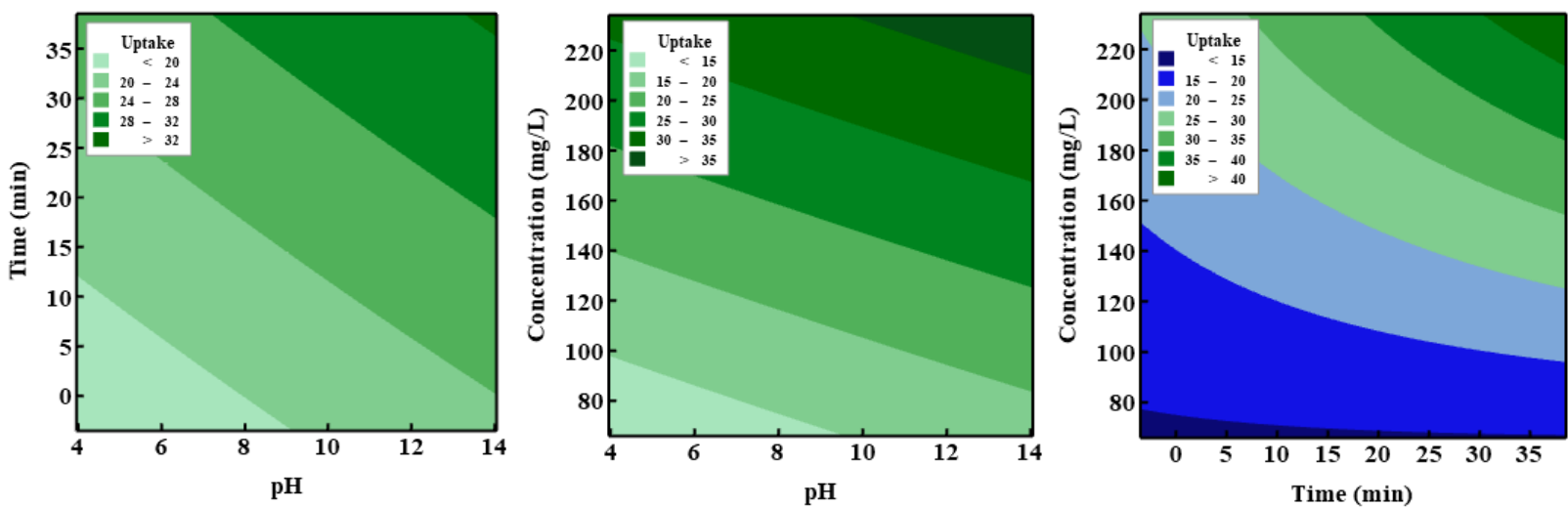

334

335

336

337

338

339

340

Fig. 5. Contour graph of strontium removal for the nZVI-Z $(\alpha=0.05)$ [Hold values:

Concentration 150 (mg/L), time 17.5 (min) and $\mathrm{pH}$ 9, respectively].
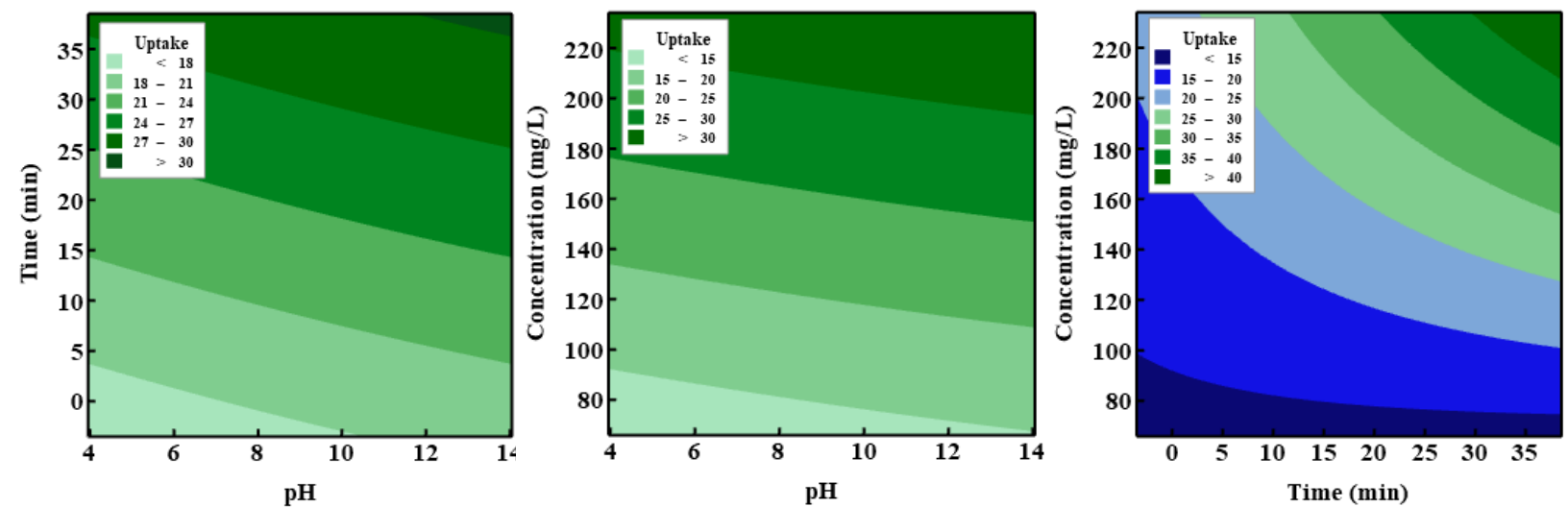

Fig. 6. Contour graph of strontium removal for the $\mathrm{nFe} / \mathrm{Cu}-\mathrm{Z}(\alpha=5 \%)$ [Hold values:

Concentration $150(\mathrm{mg} / \mathrm{L})$, time $17.5(\mathrm{~min})$ and $\mathrm{pH}$ 9, respectively] 


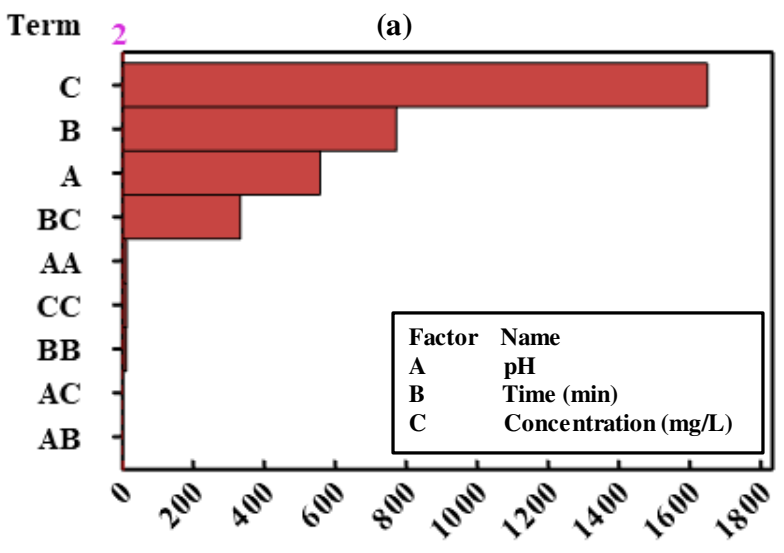

Standardized effect

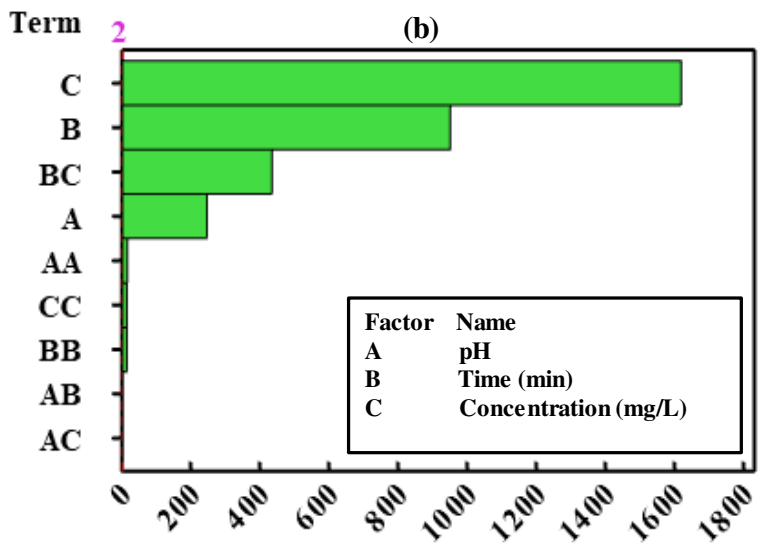

Standardized effect

Fig. 7. Pareto chart of strontium removal for a) $n Z V I-Z$ and ii) $n F e / C u-Z$ adsorbent $(\alpha=5 \%)$.

The Pareto chart clarifies whether the variables are statistically significant or not. It also helps to identify the most potential factor of the removal process. The perpendicular red das line in Fig. 7 indicates the reference line, and the effects are statistically significant if it falls on the right side of the reference line. According to Fig. 7, all effects except interaction AC and AB are statistically significant for both composites, and initial concentration has the most potential impact on strontium removal followed by contact time, $\mathrm{pH}$, and interaction $\mathrm{BC}$.

\subsection{Second-order model for the strontium removal}

For the rigorous analysis of the strontium removal, a nonlinear regression technique and the analysis of variance (ANOVA) have been conducted using the central composite design (CCD). Table 2 displayed the estimated coefficient and their standard error, $\mathrm{t}$-value, and $\mathrm{p}$-value for each main effect, quadratic effect, and interaction effect for both adsorbents.

From Table 2, it can be shown that the main effects $\mathrm{pH}$, contact time, and initial concentration are statistically significant (p-value $<0.05)$ at $5 \%$ level, which means the mean strontium removal at two different levels are not equal. Moreover, the square terms of the main effects are statistically significant, meaning that the association between the factor and the strontium removal follows a nonlinear relationship. Besides, the statistically significant interaction effect BC (contact time and initial concentration) indicates the influence of initial concentration on strontium removal is different at different levels of contact time, which coincides with the results obtained in the normal 
364 plot and main and interaction effects plot for both the adsorbent. On the contrary, the interaction 365 effects (AB and $\mathrm{AC})$ are not statistically significant.

366 The codified mathematical model of response surface method considering three factors are 367 given below:

$$
\tau=\lambda_{\mathrm{o}}+\lambda_{1} \mathrm{~A}+\lambda_{2} \mathrm{~B}+\lambda_{3} \mathrm{C}+\lambda_{4} \mathrm{~A}^{2}+\lambda_{5} \mathrm{~B}^{2}+\lambda_{6} \mathrm{C}^{2}+\lambda_{7} \mathrm{AB}+\lambda_{8} \mathrm{AC}+\lambda_{9} \mathrm{BC}+\varepsilon
$$

368

369

370

371

372

373 given as,

$$
\begin{aligned}
& \tau=24.656+2.2003 \mathrm{~A}+2.7777 \mathrm{~B}+5.9405 \mathrm{C}-0.0365 \mathrm{~A}^{2}-0.0341 \mathrm{~B}^{2}-0.0353 \mathrm{C}^{2}+ \\
& 1.5550 \mathrm{BC}+\varepsilon
\end{aligned}
$$

374 Similarly, for $\mathrm{nFe} / \mathrm{Cu}-\mathrm{Z}$, the model can be given as,

$$
\begin{gathered}
\tau=23.5142+0.8961 \mathrm{~A}+3.4769 \mathrm{~B}+5.9246 \mathrm{C}-0.04934 \mathrm{~A}^{2}-0.04639 \mathrm{~B}^{2}- \\
0.04757 \mathrm{C}^{2}+2.07333 \mathrm{BC}+\varepsilon
\end{gathered}
$$


Table 2. Response surface regression: strontium removal versus $\mathrm{pH}$, Time, Concentration.

\begin{tabular}{|c|c|c|c|c|c|c|}
\hline & \multicolumn{3}{|c|}{ nZVI-Z } & \multicolumn{3}{|c|}{$\mathrm{nFe} / \mathrm{Cu}-\mathrm{Z}$} \\
\hline Factor & $\begin{array}{l}\text { Estimate } \\
\text { (std. error.) }\end{array}$ & t-value & $\mathrm{p}$-value & $\begin{array}{l}\text { Estimate } \\
\text { (std. error) }\end{array}$ & t-value & p-value \\
\hline Intercept & $\begin{array}{c}24.656 \\
(0.0054)\end{array}$ & 4535.46 & $1.8 \times 10^{-13}$ & $\begin{array}{l}23.5142 \\
(0.0055)\end{array}$ & 4260.20 & $1.9 \times 10^{-12}$ \\
\hline $\mathbf{A}$ & $\begin{array}{c}2.2003 \\
(0.0036)\end{array}$ & 555.44 & $1.7 \times 10^{-8}$ & $\begin{array}{c}0.89618 \\
(0.00366)\end{array}$ & 244.72 & $1.6 \times 10^{-9}$ \\
\hline B & $\begin{array}{c}2.7777 \\
(0.0036)\end{array}$ & 770.12 & $1.9 \times 10^{-13}$ & $\begin{array}{l}3.47699 \\
(0.00366)\end{array}$ & 949.46 & $1.8 \times 10^{-12}$ \\
\hline $\mathbf{C}$ & $\begin{array}{c}5.9405 \\
(0.0036)\end{array}$ & 1646.97 & $1.4 \times 10^{-10}$ & $\begin{array}{l}5.92460 \\
(0.00366)\end{array}$ & 1617.83 & $1.3 \times 10^{-10}$ \\
\hline $\mathbf{A}^{2}$ & $\begin{array}{l}-0.0365 \\
(0.0035)\end{array}$ & -10.41 & $1.1 \times 10^{-2}$ & $\begin{array}{l}-0.04934 \\
(0.00356)\end{array}$ & -13.84 & $1.2 \times 10^{-2}$ \\
\hline $\mathbf{B}^{2}$ & $\begin{array}{l}-0.0341 \\
(0.0035)\end{array}$ & -9.74 & $1.1 \times 10^{-2}$ & $\begin{array}{l}-0.04639 \\
(0.00356)\end{array}$ & -13.01 & $1.6 \times 10^{-3}$ \\
\hline $\mathbf{C}^{2}$ & $\begin{array}{l}-0.0353 \\
(0.0035)\end{array}$ & -10.07 & $9.3 \times 10^{-2}$ & $\begin{array}{l}-0.04757 \\
(0.00256)\end{array}$ & -13.34 & $9.4 \times 10^{-3}$ \\
\hline $\mathbf{A B}$ & $\begin{array}{c}0.0016 \\
(0.0047)\end{array}$ & 0.35 & 0.725 & $\begin{array}{c}0.00083 \\
(0.00478)\end{array}$ & 0.17 & 0.8620 \\
\hline $\mathrm{AC}$ & $\begin{array}{l}-0.0024 \\
(0.0047)\end{array}$ & -0.51 & 0.610 & $\begin{array}{l}-0.00000 \\
(0.00478)\end{array}$ & -0.00 & 0.999 \\
\hline BC & $\begin{array}{c}1.5550 \\
(0.0047)\end{array}$ & 329.96 & $2.0 \times 10^{-3}$ & $\begin{array}{l}2.07333 \\
(0.00478)\end{array}$ & 433.32 & $1.9 \times 10^{-3}$ \\
\hline
\end{tabular}


393 Analysis of variance is the process of distributing total variation contained in a data set into two 394 components, which are assignable causes of variation and unassignable causes (error) of variation. 395 ANOVA is used in this study to assess whether or not the average effects of different variables at 396 different levels are equal. A comparison of the strontium removal at different levels of factors 397 identifies the most influential factors and their effects. Table 3 displayed an adjusted sum of 398 squares, the adjusted mean sum of squares, F-value, and P-value, and P-value less than 0.01 399 indicates the effect is statistically significant at $1 \%$ level. Both main and interaction effects, 400 excluding the $\mathrm{AB}$ and $\mathrm{AC}$ interaction effects, have been shown to be statistically significant. 401 Results indicated that the sum of square (SS) of factor C is the highest (1445.86 and 1438.11 for $402 \mathrm{nZVI}-\mathrm{Z}$ and $\mathrm{nFe} / \mathrm{Cu}-\mathrm{Z}$, respectively), which indicates initial concentration is the most explainable 403 variable followed by contact time and $\mathrm{pH}$ for strontium removal for both adsorbents. Lack of fit 404 for both adsorbents is insignificant, which means the model does not suffer from a lack of fit and 405 no need to introduce higher order terms in the analyzed model. The high $\mathrm{R}^{2}$ value for both 406 adsorbents indicates the model fits well.

407

408

409

410

411

412

413

414

415

416

417 
Table 3. Optimization of factors by using ANOVA technique.

\begin{tabular}{|c|c|c|c|c|c|c|c|}
\hline \multirow{2}{*}{\multicolumn{2}{|c|}{ Factor df }} & \multicolumn{3}{|c|}{ nZVI-Z } & \multicolumn{3}{|c|}{$\mathrm{nFe} / \mathrm{Cu}-\mathrm{Z}$} \\
\hline & & SS (MS) & F-value & p-value & SS (MS) & F-value & p-value \\
\hline \multicolumn{8}{|c|}{ Linear effect } \\
\hline A & 1 & $\begin{array}{c}164.45 \\
(164.45)\end{array}$ & 308510.62 & $2.1 \times 10^{-8}$ & $\begin{array}{c}32.91 \\
(32.91)\end{array}$ & 59888.01 & $2 \times 10^{-11}$ \\
\hline B & 1 & $\begin{array}{c}316.13 \\
(316.13)\end{array}$ & 593082.62 & $2.0 \times 10^{-16}$ & $\begin{array}{c}495.31 \\
(495.31)\end{array}$ & 901476.55 & $2 \times 10^{-12}$ \\
\hline $\mathrm{C}$ & 1 & $\begin{array}{r}1445.86 \\
(1445.86)\end{array}$ & 2712501.57 & $2.3 \times 10^{-10}$ & $\begin{array}{c}1438.11 \\
(1438.11)\end{array}$ & 2617381.9 & $2 \times 10^{-12}$ \\
\hline
\end{tabular}

Quadratic effect

\begin{tabular}{|c|c|c|c|c|c|c|c|}
\hline$A^{2}$ & 1 & $0.06(0.06)$ & 108.31 & $2.1 \times 10^{-10}$ & $0.11(0.11)$ & 191.52 & $2 \times 10^{-3}$ \\
\hline $\mathrm{B}^{2}$ & 1 & $0.05(0.05)$ & 94.78 & $2.0 \times 10^{-9}$ & $0.09(0.09)$ & 169.33 & $2 \times 10^{-4}$ \\
\hline $\mathrm{C}^{2}$ & 1 & $0.05(0.05)$ & 101.43 & $2.2 \times 10^{-11}$ & $0.10(0.10)$ & 178.04 & $2 \times 10^{-3}$ \\
\hline \multicolumn{8}{|c|}{ 2-Way interaction } \\
\hline $\mathrm{AB}$ & 1 & $0.00(0.00)$ & 0.13 & 0.725 & $0.000(0.000)$ & 0.03 & 0.862 \\
\hline $\mathrm{AC}$ & 1 & $0.00(0.00)$ & 0.26 & 0.610 & $0.000(0.000)$ & 0.00 & 1.00 \\
\hline $\mathrm{BC}$ & 1 & $58.03(58.03)$ & 108871.72 & $2.2 \times 10^{-11}$ & $\begin{array}{c}103.17 \\
(103.17)\end{array}$ & 187769.87 & $2 \times 10^{-12}$ \\
\hline Error & 50 & $0.003(0.00)$ & & & $0.000(0.000)$ & & \\
\hline $\begin{array}{l}\text { Lack- } \\
\text { of-Fit }\end{array}$ & 5 & $0.00(0.00)$ & 0.53 & 0.751 & $0.00(0.00)$ & 0.30 & 0.909 \\
\hline \multirow[t]{2}{*}{$\begin{array}{l}\text { Pure } \\
\text { Error }\end{array}$} & 45 & $0.03(0.00)$ & & & $0.03(0.00)$ & & \\
\hline & & \multicolumn{3}{|c|}{$\mathrm{R}^{2}=100.00 \%$ and $\mathrm{R}^{2}(\mathrm{adj})=98.97 \%$} & \multicolumn{3}{|c|}{$\mathrm{R}^{2}=100.00 \%$ and $\mathrm{R}^{2}(\mathrm{adj})=99.68 \%$} \\
\hline
\end{tabular}




\subsection{Validation of assumption}

3.8.1 Residuals versus fits plot

The required assumption of the distribution, such as randomness and constant variance of residuals, can be verified by using the residual versus fit graph presented in Fig. 8. As the residuals are randomly scattered on both sides of the zero line, and there is no recognizable pattern of the residuals, we can conclude that the model meets the given assumptions.
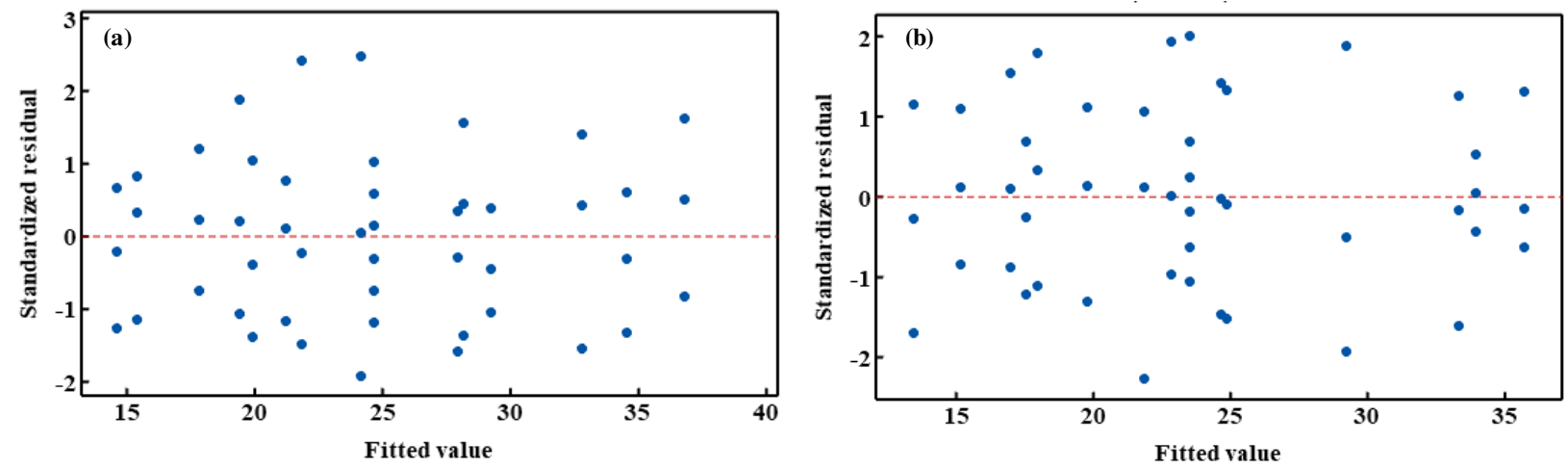

Fig. 8. Residual vs. Fits plots of strontium removal for a) nZVI-Z and ii) nFe/Cu-Z adsorbent.

\subsubsection{Residuals versus order plot}

The assumption of independent residuals from one another can be checked by the residual versus order plot presented in Fig. 9 for the strontium removal process. Residuals in time order did not show any pattern, and it falls randomly around the centerline for both adsorbents that indicates the residuals are independent of one another.
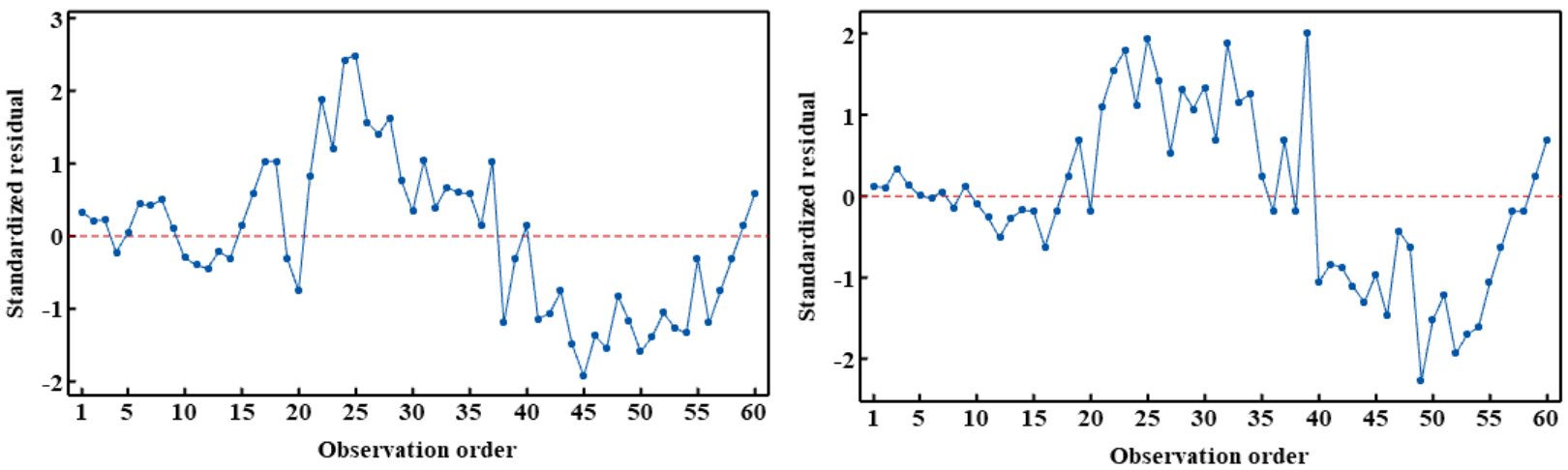

Fig. 9. Residual vs. order plots of strontium removal for a) nZVI-Z and ii) nFe/Cu-Z adsorbent. 


\subsubsection{Normal probability plot}

The assumption of normally distributed residuals can be verified by using the normal probability plot. The normal plot of the residuals for strontium removal using two different nanocomposites is portrayed in Fig. 10. The residuals showed a more or less straight line meaning that residuals meet the normality assumption.
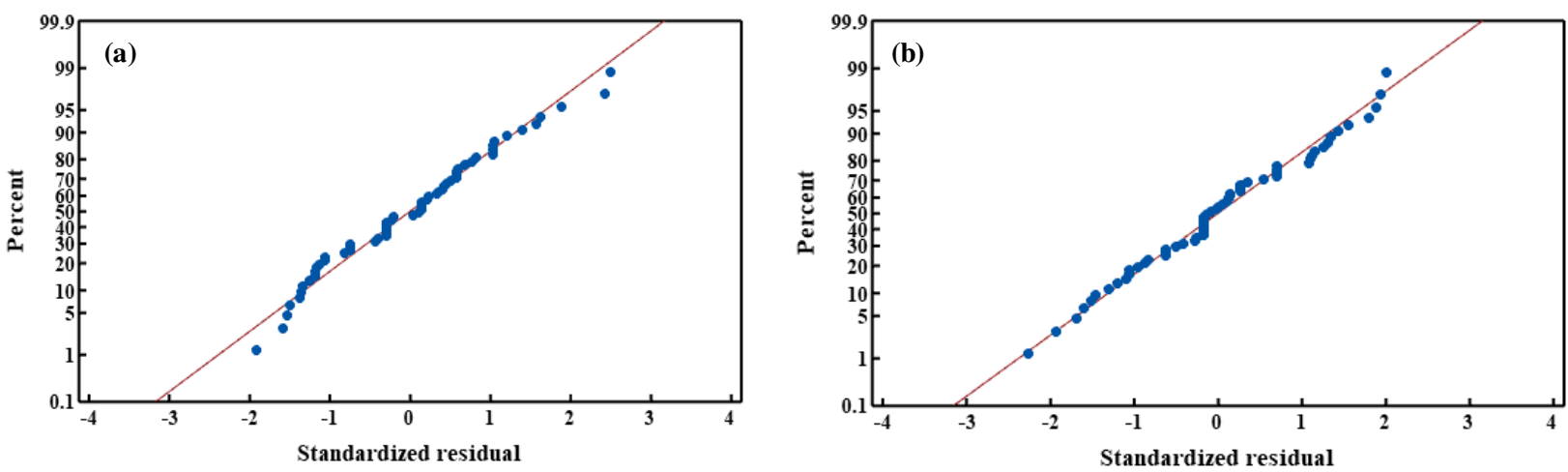

Fig. 10. Normal plots of residuals for a) nZVI-Z and ii) $n F e / C u-Z$ adsorbent $(\alpha=5 \%)$.

\subsection{Response optimization}

The optimization plot displays the effect of factors on the predicted responses (strontium removal). It identifies i) optimum settings of the predictors and ii) point estimate and prediction interval of the responses. Response optimization plots of strontium removal for two different nanocomposites are displayed in Fig. 11. The current factor settings are $\mathrm{pH}=14.0454$, contact time $=38.5224$ minutes, and initial concentration $=234.0896(\mathrm{mg} / \mathrm{L})$. The goal of this study was to maximize the removal of strontium. Its predicted value is 46.7847 , and the $95 \%$ prediction interval (PI) is $(46.7099,46.8596)$ for the nZVI-Z adsorbent. Narrower prediction interval (PI) indicates a more precise prediction of the strontium removal. 
(a)

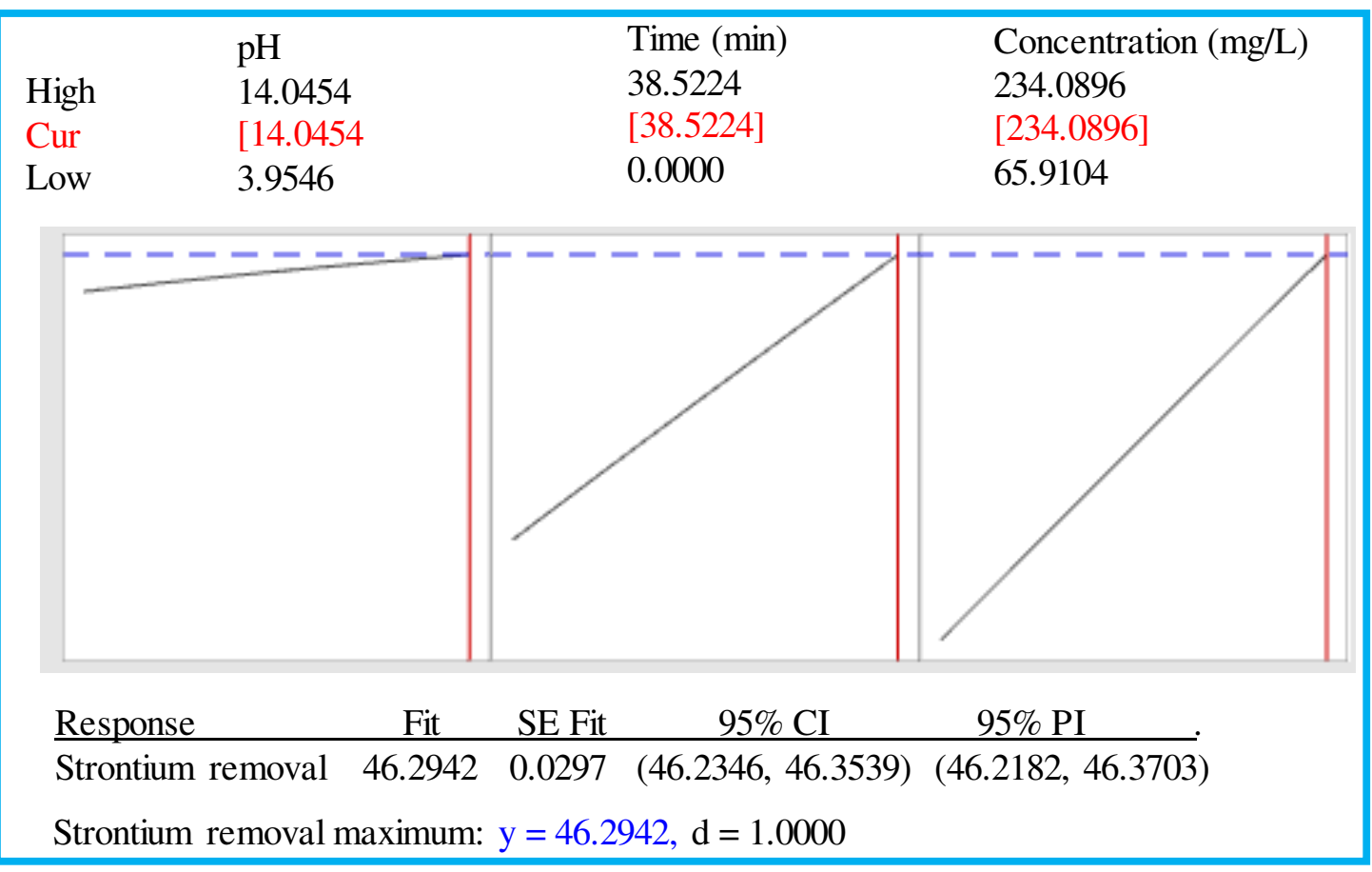

(b)

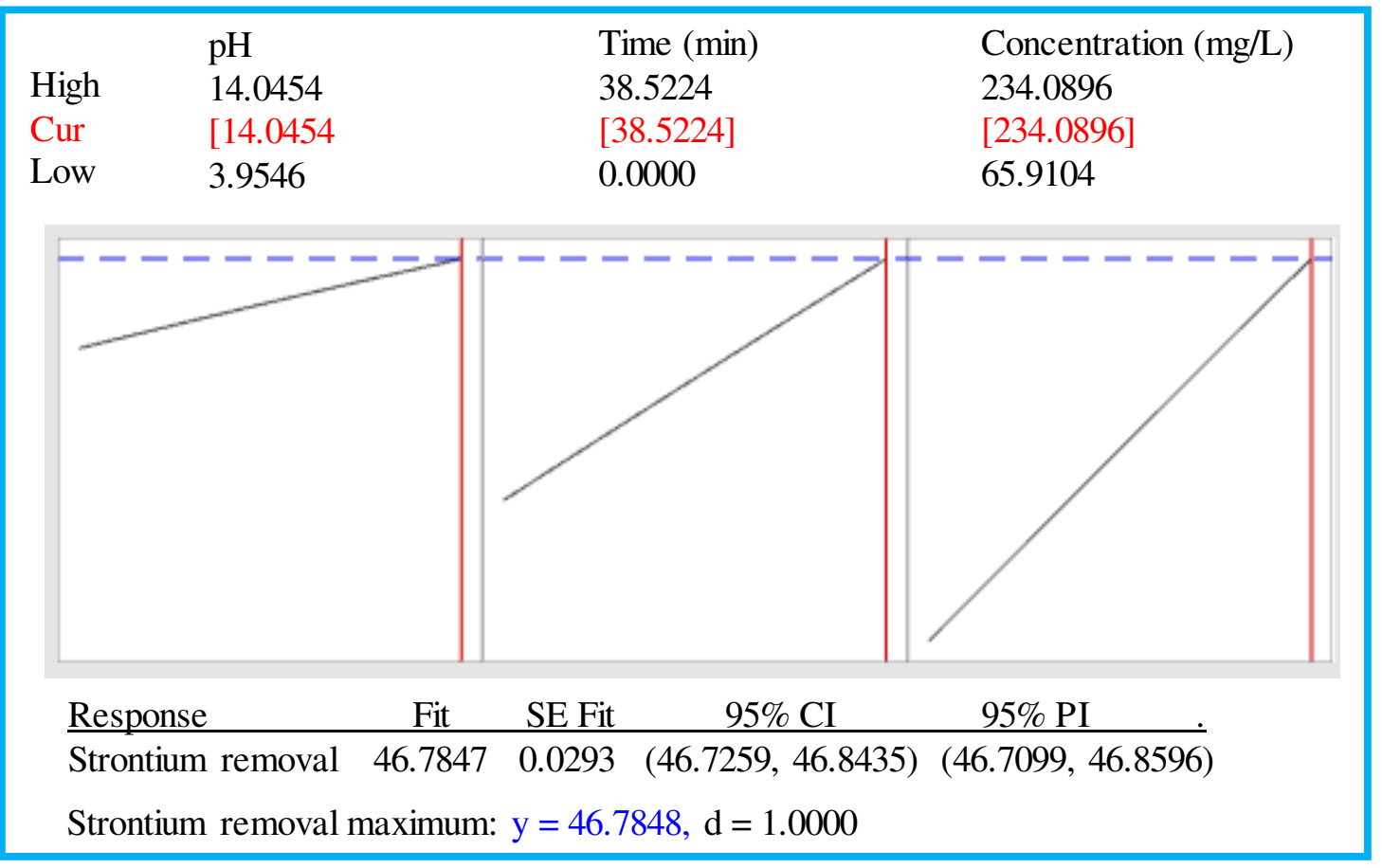

463 Fig. 11. Response optimization plots of strontium removal for a) $n Z V I-Z$ and $b) n F e / C u-Z$ 464 adsorbent $(\alpha=5 \%)$. 


\subsection{Isotherm model fitting}

467 In various studies, few isothermal models such as Freundlich and Langmuir have been applied 468 to remove the radioactive materials from wastewater (Piccin et al. 2017; Eljamal et al. 2019; 469 Shubair et al. 2019; Xanthopoulou et al. 2021). In this study, five isotherm models are fitted with 470 experimental results, and the best isothermal model is diagnosed. The relation between the removal 471 of strontium and concentrations is presented in Fig. 12. It can be stated that the concentration of 472 strontium is positively associated with strontium removal.

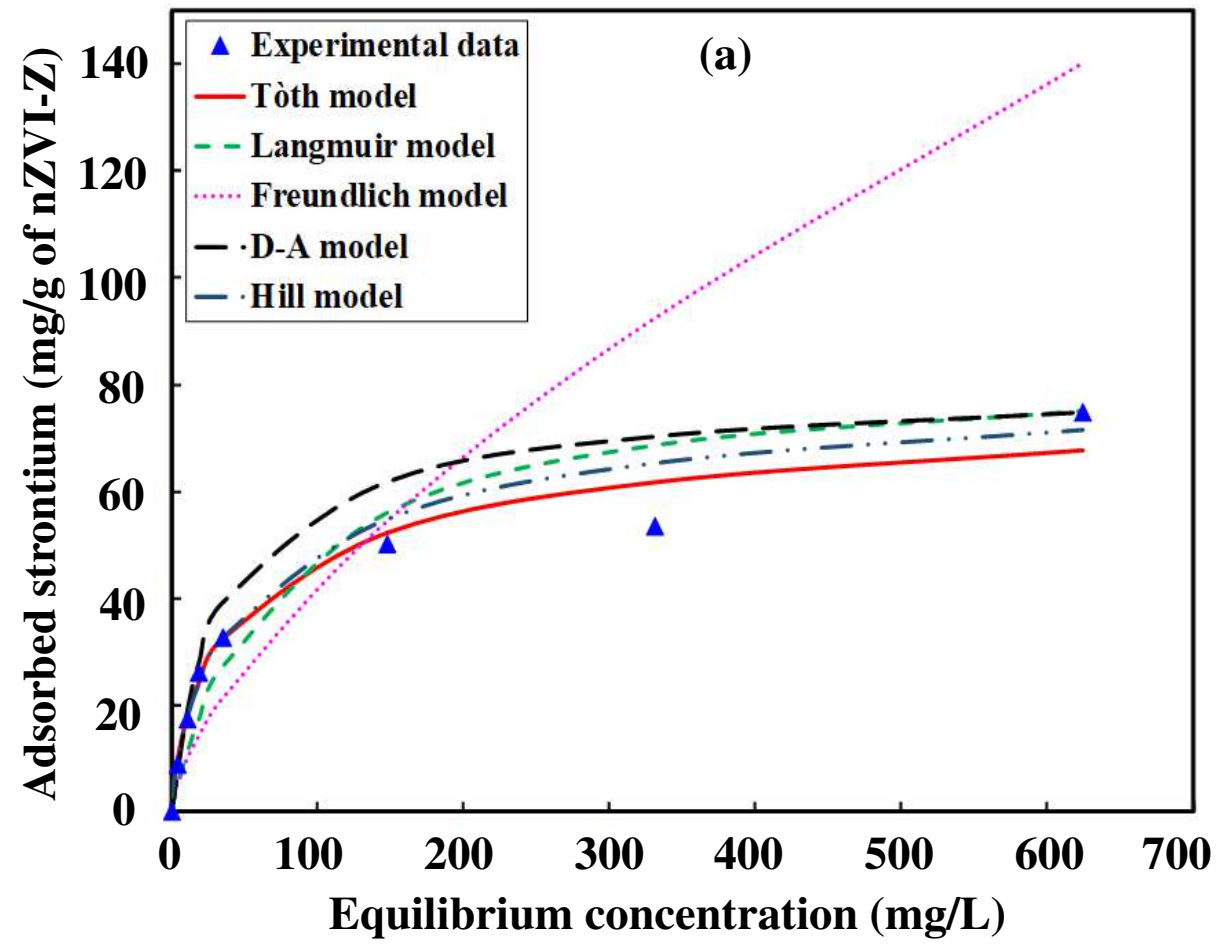




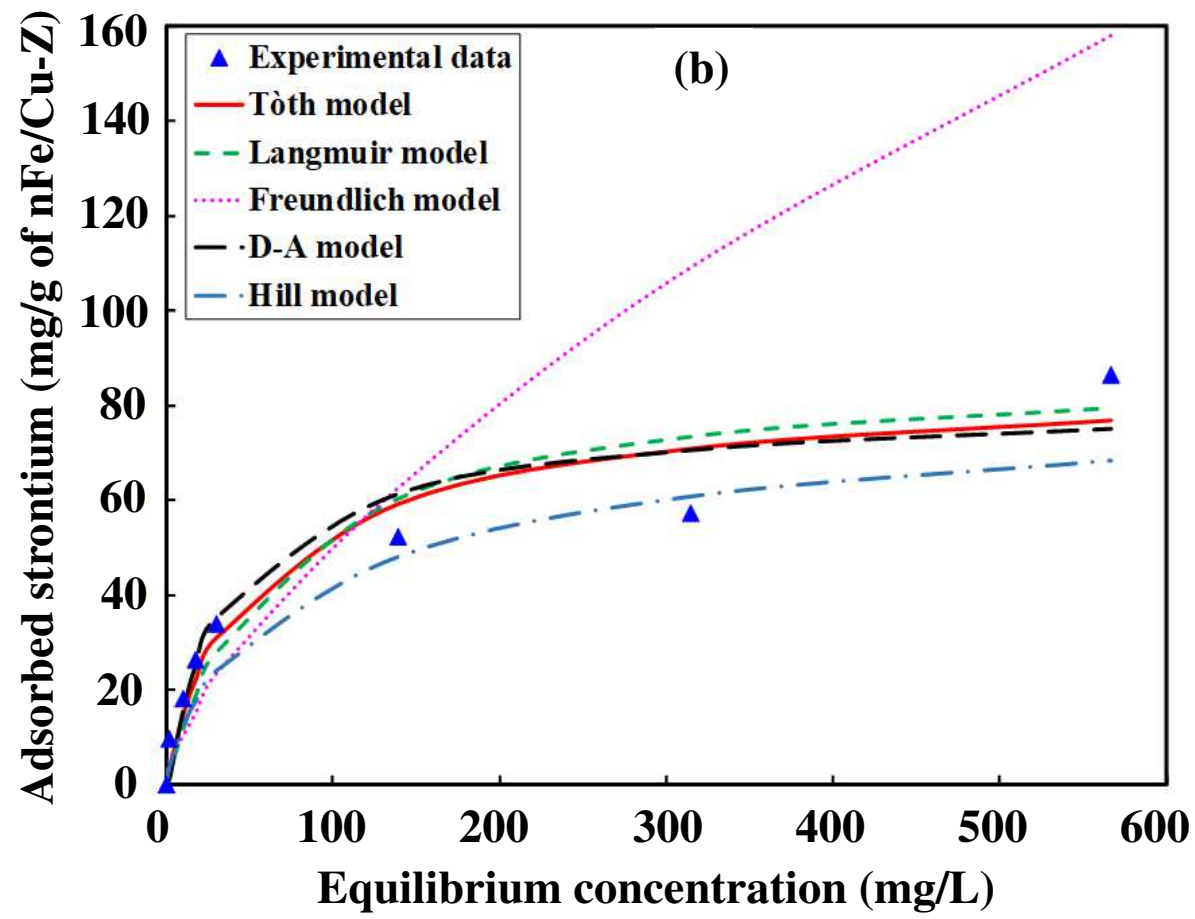

Fig. 12. Sorption isotherm of models onto (a) nZVI-Z and (b) nFe/Cu-Z using RMSD. Fixed parameter: dosage $=5 \mathrm{gL}^{-1}, \mathrm{pH}=6$ and temperature $=298 \mathrm{~K}$ ).

Table 4 displays the estimated parameters and RMSD values of the fitted models. According to the values of $\mathrm{R}^{2}$, it can be stated that strontium removal is adequately described by these models. Results suggested that the Tóth model is lower than that of other models based on RMSD value, suggesting that the Tóth model performs better than other models. The value of $\mathrm{n}$ used in the Freundlich model is greater than unity, meaning adsorption increases with concentration increases. Based on $W_{0}$ and $\mathrm{K}_{\mathrm{f}}$, it is mentioned that the sorption capability of the $\mathrm{nFe} / \mathrm{Cu}-\mathrm{Z}$ adsorbent is greater than that of nZVI-Z. 
Table 4. Parameter estimation of different isotherms models.

\begin{tabular}{|c|c|c|c|c|c|c|c|}
\hline Model & Adsorbent & & & Paramete & & & \\
\hline Tóth & & $\mathrm{W}_{0}\left(\mathrm{mgg}^{-1}\right)$ & $b_{0}\left(\mathrm{Lmg}^{-1}\right)$ & $\mathbf{Q}\left(\mathrm{Jmol}^{-1}\right)$ & $t(-)$ & $\mathbf{R}^{2}$ & RMSD \\
\hline & nZVI-Z & 85 & 7.55E-05 & 15909.22 & 0.726 & 0.9957 & 3.947 \\
\hline & $\mathrm{nFe} / \mathrm{Cu}-\mathrm{Z}$ & 89 & 8.69E-05 & 13821.74 & 0.812 & 0.9978 & 6.984 \\
\hline Langmuir & & $\mathrm{W}_{0}\left(\mathrm{mgg}^{-1}\right)$ & $\mathrm{K}_{\mathrm{L}}\left(\mathrm{Lmg}^{-1}\right)$ & & & & \\
\hline & nZVI-Z & 84.12 & $5.21 \mathrm{E}-05$ & & & 0.9947 & 7.301 \\
\hline & nFe/Cu-Z & 88.74 & $5.23 \mathrm{E}-05$ & & & 0.9952 & 8.313 \\
\hline Freundlich & & $K_{f}\left(\mathrm{mgg}^{-1}\right)($ & $\left.\mathrm{mgL}^{-1}\right)^{-(1 / n)}$ & n (-) & & & \\
\hline & nZVI-Z & 2.03 & & 1.52 & & 0.821 & 27.675 \\
\hline & nFe/Cu-Z & 2.05 & & 1.46 & & 0.792 & 39.132 \\
\hline D-A & & $\mathrm{W}_{0}\left(\mathrm{mgg}^{-1}\right)$ & $E\left(J^{-1}\right)$ & n (-) & & & \\
\hline & nZVI-Z & 82 & 338.64 & 7 & & 0.972 & 7.109 \\
\hline & nFe/Cu-Z & 83 & 336.30 & 7.21 & & 0.982 & 7.186 \\
\hline Hill & & $\mathrm{W}_{0}\left(\mathrm{mgg}^{-1}\right)$ & $\mathbf{n}_{\mathbf{h}}$ & $\mathbf{K}_{\mathbf{D}}$ & & & \\
\hline & nZVI-Z & 85 & 0.75 & 00356 & & 0.976 & 4.4911 \\
\hline & nFe/Cu-Z & 88 & 0.76 & 0046 & & 0.982 & 8.0770 \\
\hline
\end{tabular}

\section{Conclusions}

To explore the impact of different factors and their interaction effects on the efficacy of strontium removal, response surface methodology based on the central composite design was used to identify the optimal conditions for removing strontium from contaminated water using ironbased nanoparticles-zeolite. The main findings can be summarized as follows:

1) The nanocomposite $n Z \mathrm{VI}-\mathrm{Z}$ and $\mathrm{nFe} / \mathrm{Cu}-\mathrm{Z}$ are efficient adsorbents to extract strontium from contaminated water.

2) Regression results showed that initial concentration, contact time, and $\mathrm{pH}$ have a statistically significant impact on the process of removing strontium, and concentration was found to be the most potential factor followed by contact time for this removal process. 
534 No external funding.

\section{Declarations}

Not application

\section{Consent for publication}

Not applicable request.

3) The statistically significant effect of the interaction between the initial concentration and contact time was observed and suggested that the impact of the initial concentration on the removal of strontium differs at different contact time levels. Subsequently, the chemicals used in experimental work and research costs may be reduced.

4) Tóth, Langmuir, Dubinin-Astakhov (D-A), Freundlich, and Hill models were fitted with the removal data and observed that the Tóth model performed very well, followed by Hill and D-A model based on RMSD. The fitting of Tóth, Dubinin-Astakhov (D-A), and Hill models certainly contributes to existing literature, as only Langmuir and Freundlich models are available in previous studies.

The findings may contribute to developing an efficient strontium removal system from wastewater. It is an emerging issue worldwide, particularly in Japan, after the destruction of the Fukushima Daiichi Nuclear Power Plant.

\section{Ethics approval and consent to participate}

\section{Availability of data and materials}

All data used and analyzed in this study are available from the corresponding author on reasonable 


\section{Authors' contributions}

537 Shamal Chandra Karmaker: Conceptualization, Formal analysis, Methodology, Writing-original draft. Osama Eljamal: Investigation, Experiments, Writing-review \& editing. Bidyut Baran Saha: Conceptualization, Methodology, Writing-review \& editing, Supervision.

\section{References}

Abdulgader M, Yu QJ, Zinatizadeh AA, et al. (2020) Application of response surface methodology (RSM) for process analysis and optimization of milk processing wastewater treatment using

Ambashta RD, Sillanpää M (2010) Water purification using magnetic assistance: A review. J Hazard Mater 180:38-49. https://doi.org/10.1016/j.jhazmat.2010.04.105

Amen TWM, Eljamal O, Khalil AME, Matsunaga N (2017) Biochemical methane potential enhancement of domestic sludge digestion by adding pristine iron nanoparticles and iron nanoparticles coated zeolite compositions. J Environ Chem Eng 5:5002-5013. https://doi.org/10.1016/j.jece.2017.09.030

Amen TWM, Eljamal O, Khalil AME, Matsunaga N (2018) Wastewater degradation by iron/copper nanoparticles and the microorganism growth rate. J Environ Sci (China) 74:1931. https://doi.org/10.1016/j.jes.2018.01.028

Aoyama M, Tsumune D, Inomata Y, Tateda Y (2020) Mass balance and latest fluxes of radiocesium derived from the Fukushima accident in the western North Pacific Ocean and coastal regions of Japan. J Environ Radioact 217:106206. https://doi.org/10.1016/j.jenvrad.2020.106206

Bahrami M, Amiri MJ, Bagheri F (2019) Optimization of the lead removal from aqueous solution using two starch based adsorbents: Design of experiments using response surface methodology (RSM). J Environ Chem Eng 7:102793. https://doi.org/10.1016/j.jece.2018.11.038

Bingöl D (2011) Removal of cadmium (II) from aqueous solutions using a central composite design. Fresenius Environ Bull 20:2704-2709

Can MY, Yildiz E (2006) Phosphate removal from water by fly ash: Factorial experimental design. J Hazard Mater 135:165-170. https://doi.org/10.1016/j.jhazmat.2005.11.036 
Dong S, Sartaj M (2016) Statistical analysis and optimization of ammonia removal from landfill leachate by sequential microwave/aeration process using factorial design and response surface methodology. J Environ Chem Eng 4:100-108. https://doi.org/10.1016/j.jece.2015.10.029

Echeverría JC, Zarranz I, Estella J, Garrido JJ (2005) Simultaneous effect of pH, temperature, ionic strength, and initial concentration on the retention of lead on illite. Appl Clay Sci 30:103-115. https://doi.org/10.1016/j.clay.2005.03.006

El-Kamash AM (2008) Evaluation of zeolite A for the sorptive removal of Cs+ and Sr2+ ions from aqueous solutions using batch and fixed bed column operations. J Hazard Mater 151:432445. https://doi.org/10.1016/j.jhazmat.2007.06.009

Eljamal O, Shubair T, Tahara A, et al. (2019) Iron based nanoparticles-zeolite composites for the removal of cesium from aqueous solutions. $J$ Mol Liq 277:613-623. https://doi.org/10.1016/j.molliq.2018.12.115

Faghihian H, Iravani M, Moayed M, Ghannadi-Maragheh M (2013) Preparation of a novel PANzeolite nanocomposite for removal of $\mathrm{Cs}+$ and $\mathrm{Sr} 2+$ from aqueous solutions: Kinetic, equilibrium, and thermodynamic studies. Chem Eng J 222:41-48. https://doi.org/10.1016/j.cej.2013.02.035

Geyikçi F, Büyükgüngör H (2013) Factorial experimental design for adsorption silver ions from water onto montmorillonite. Acta Geodyn Geomater 10:363-370

Ghaedi AM, Panahimehr M, Nejad ARS, et al. (2018) Factorial experimental design for the optimization of highly selective adsorption removal of lead and copper ions using metal organic framework MOF-2 (Cd). J Mol Liq 272:15-26. https://doi.org/10.1016/j.molliq.2018.09.051

Ghafarzadeh M, Abedini R, Rajabi R (2017) Optimization of ultrasonic waves application in municipal wastewater sludge treatment using response surface method. J Clean Prod 150:361-370. https://doi.org/10.1016/j.jclepro.2017.02.159

Hesas RH, Baei MS, Rostami H, et al. (2019) An investigation on the capability of magnetically separable Fe3O4/mordenite zeolite for refinery oily wastewater purification. J Environ Manage 241:525-534. https://doi.org/10.1016/j.jenvman.2018.09.005

Hong HJ, Jeong HS, Kim BG, et al. (2016a) Highly stable and magnetically separable alginate/Fe3O4 composite for the removal of strontium ( $\mathrm{Sr}$ ) from seawater. Chemosphere 
165:231-238. https://doi.org/10.1016/j.chemosphere.2016.09.034

Hong HJ, Ryu J, Park IS, et al. (2016b) Investigation of the strontium (Sr(II)) adsorption of an alginate microsphere as a low-cost adsorbent for removal and recovery from seawater. J Environ Manage 165:263-270. https://doi.org/10.1016/j.jenvman.2015.09.040

Hua M, Zhang S, Pan B, et al. (2012) Heavy metal removal from water/wastewater by nanosized metal oxides: A review. J Hazard Mater 211-212:317-331. https://doi.org/10.1016/j.jhazmat.2011.10.016

Jaria G, Silva CP, Oliveira JABP, et al. (2019) Production of highly efficient activated carbons from industrial wastes for the removal of pharmaceuticals from water-A full factorial design. J Hazard Mater 370:212-218. https://doi.org/10.1016/j.jhazmat.2018.02.053

Kumari M, Gupta SK (2019) Response surface methodological (RSM) approach for optimizing the removal of trihalomethanes (THMs) and its precursor's by surfactant modified magnetic nanoadsorbents (sMNP) - An endeavor to diminish probable cancer risk. Sci Rep 9:1-11. https://doi.org/10.1038/s41598-019-54902-8

Lee KY, Kim KW, Park M, et al. (2016) Novel application of nanozeolite for radioactive cesium removal from high-salt wastewater. Water Res 95:134-141. https://doi.org/10.1016/j.watres.2016.02.052

Liu CH, Shih YJ, Huang YH, Huang CP (2014) Kinetic and thermodynamic studies for adsorptive removal of Sr2+ using waste iron oxide. J Taiwan Inst Chem Eng 45:914-920. https://doi.org/10.1016/j.jtice.2013.08.012

Maamoun I, Eljamal O, Falyouna O, et al. (2020) Multi-objective optimization of permeable reactive barrier design for $\mathrm{Cr}(\mathrm{VI})$ removal from groundwater. Ecotoxicol Environ Saf 200:110773. https://doi.org/10.1016/j.ecoenv.2020.110773

Mao Y, Yu S, Li P, et al. (2021) A novel magnesium-rich tricalcium aluminate for simultaneous removal of ammonium and phosphorus: Response surface methodology and mechanism investigation. Environ Res 195:110719. https://doi.org/10.1016/j.envres.2021.110719

Mohammed IY, Abakr YA, Yusup S, Kazi FK (2017) Valorization of Napier grass via intermediate pyrolysis: Optimization using response surface methodology and pyrolysis products characterization. J Clean Prod 142:1848-1866. https://doi.org/10.1016/j.jclepro.2016.11.099

Pal A, El-Sharkawy II, Saha BB, et al. (2016) Experimental investigation of CO2 adsorption onto 

Therm Eng 109:304-311. https://doi.org/10.1016/j.applthermaleng.2016.08.031

631

632

Pal A, Kil HS, Mitra S, et al. (2017) Ethanol adsorption uptake and kinetics onto waste palm trunk and mangrove based activated carbons. Appl Therm Eng 122:389-397. https://doi.org/10.1016/j.applthermaleng.2017.04.099

Perez Mora B, Bellú S, Mangiameli MF, et al. (2019) Response surface methodology and optimization of arsenic continuous sorption process from contaminated water using chitosan. J Water Process Eng 32:100913. https://doi.org/10.1016/j.jwpe.2019.100913

Piccin JS, Cadaval TRS, de Pinto LAA, Dotto GL (2017) Adsorption Isotherms in Liquid Phase: Experimental, Modeling, and Interpretations. In: Bonilla-Petriciolet A, Mendoza-Castillo DI, Reynel-Ávila HE (eds) Adsorption Processes for Water Treatment and Purification. Springer International Publishing, Cham, pp 19-51

Ponnusami V, Krithika V, Madhuram R, Srivastava SN (2007) Biosorption of reactive dye using acid-treated rice husk: Factorial design analysis. J Hazard Mater 142:397-403. https://doi.org/10.1016/j.jhazmat.2006.08.040

Rahman MM, Karmaker SC, Pal A, et al (2020a) Statistical techniques for the optimization of cesium removal from aqueous solutions onto iron-based nanoparticle-zeolite composites. Environ Sci Pollut Res. https://doi.org/10.1007/s11356-020-11258-1

Rahman MM, Muttakin M, Pal A, et al. (2019) A Statistical Approach to Determine Optimal Models for IUPAC-Classified Adsorption Isotherms. Energies 12:4565. https://doi.org/10.3390/en12234565

Rahman MM, Pal A, Uddin K, et al. (2018) Statistical Analysis of Optimized Isotherm Model for Maxsorb III/Ethanol and Silica Gel/Water Pairs. Evergreen 5:1-12. https://doi.org/10.5109/2174852

Rahman N, Khan MF, Nasir M (2020b) Experimental design approach for optimization of Pb(II) removal from aqueous solution using poly-o-toluidine/stannic(IV) triethanolamine as adsorbent. Environ Technol Innov 17:100634. https://doi.org/10.1016/j.eti.2020.100634

Ramanayaka S, Tsang DCW, Hou D, et al. (2020) Green synthesis of graphitic nanobiochar for the removal of emerging contaminants in aqueous media. Sci Total Environ 706:135725. https://doi.org/10.1016/j.scitotenv.2019.135725

Ranic M, Nikolic M, Pavlovic M, et al. (2014) Optimization of microwave-assisted extraction of 
natural antioxidants from spent espresso coffee grounds by response surface methodology. $\mathrm{J}$ Clean Prod 80:69-79. https://doi.org/10.1016/j.jclepro.2014.05.060

Rêgo T V., Cadaval TRS, Dotto GL, Pinto LAA (2013) Statistical optimization, interaction analysis and desorption studies for the azo dyes adsorption onto chitosan films. J Colloid Interface Sci 411:27-33. https://doi.org/10.1016/j.jcis.2013.08.051

Rocky KA, Pal A, Moniruzzaman M, Saha BB (2019) Adsorption characteristics and thermodynamic property fields of polymerized ionic liquid and polyvinyl alcohol based composite/CO2 pairs. J Mol Liq 294:111555. https://doi.org/10.1016/j.molliq.2019.111555

Ryu J, Kim S, Hong HJ, et al. (2016) Strontium ion (Sr2+) separation from seawater by hydrothermally structured titanate nanotubes: Removal vs. recovery. Chem Eng J 304:503510. https://doi.org/10.1016/j.cej.2016.06.131

Saadat S, Karimi-Jashni A (2011) Optimization of Pb(II) adsorption onto modified walnut shells using factorial design and simplex methodologies. Chem Eng J 173:743-749. https://doi.org/10.1016/j.cej.2011.08.042

Seki Y, Seyhan S, Yurdakoc M (2006) Removal of boron from aqueous solution by adsorption on A12O3 based materials using full factorial design. J Hazard Mater 138:60-66. https://doi.org/10.1016/j.jhazmat.2006.05.033

Shahnaz T, Sharma V, Subbiah S, Narayanasamy S (2020) Multivariate optimisation of Cr (VI), $\mathrm{Co}$ (III) and $\mathrm{Cu}$ (II) adsorption onto nanobentonite incorporated nanocellulose/chitosan aerogel using response surface methodology. J Water Process Eng 36:101283. https://doi.org/10.1016/j.jwpe.2020.101283

Shibata A, Koma Y, Ohi T (2016) Estimation of the inventory of the radioactive wastes in Fukushima Daiichi NPS with a radionuclide transport model in the contaminated water. J Nucl Sci Technol 53:1933-1942. https://doi.org/10.1080/00223131.2016.1196625

Shubair T, Eljamal O, Matsunaga N (2018) Nano-Fe / Cu particles for the remediation of cesium contaminated solutions. Proc Int Exch Innov Conf Eng Sci 4:60-63

Shubair T, Eljamal O, Tahara A, et al. (2019) Preparation of new magnetic zeolite nanocomposites for removal of strontium from polluted waters. $J$ Mol Liq 288:111026. https://doi.org/10.1016/j.molliq.2019.111026

Tauanov Z, Tsakiridis PE, Mikhalovsky S V., Inglezakis VJ (2018) Synthetic coal fly ash-derived zeolites doped with silver nanoparticles for mercury (II) removal from water. J Environ 
Manage 224:164-171. https://doi.org/10.1016/j.jenvman.2018.07.049

Vipin AK, Ling S, Fugetsu B (2016) Removal of Cs+ and Sr2+ from water using MWCNT reinforced Zeolite-A beads. Microporous Mesoporous Mater 224:84-88. https://doi.org/10.1016/j.micromeso.2015.11.024

Wang C, Wang H, Liu Y, Huang L (2016) Optimization of surface treatment for flotation separation of polyvinyl chloride and polyethylene terephthalate waste plastics using response $\begin{array}{lllll}\text { surface methodology. } & \text { J }\end{array}$ https://doi.org/10.1016/j.jclepro.2016.08.111

Wang T, Zhou Y, Cao S, et al. (2019) Degradation of sulfanilamide by Fenton-like reaction and optimization using response surface methodology. Ecotoxicol Environ Saf 172:334-340. https://doi.org/10.1016/j.ecoenv.2019.01.106

Wang W, Zhou M, Mao Q, et al. (2010) Novel NaY zeolite-supported nanoscale zero-valent iron as an efficient heterogeneous Fenton catalyst. Catal Commun 11:937-941. https://doi.org/10.1016/j.catcom.2010.04.004

Xanthopoulou M, Giliopoulos D, Tzollas N, et al. (2021) Phosphate removal using polyethylenimine functionalized silica-based materials. Sustain 13:1-17. https://doi.org/10.3390/su13031502

Yildirim NC, Tanyol M, Yildirim N, et al. (2018) Biochemical responses of Gammarus pulex to malachite green solutions decolorized by Coriolus versicolor as a biosorbent under batch adsorption conditions optimized with response surface methodology. Ecotoxicol Environ Saf 156:41-47. https://doi.org/10.1016/j.ecoenv.2018.02.059

Zhao S, Chen Z, Shen J, et al. (2017) Response surface methodology investigation into optimization of the removal condition and mechanism of $\mathrm{Cr}(\mathrm{VI})$ by Na2SO3/CaO . J Environ Manage 202:38-45. https://doi.org/10.1016/j.jenvman.2017.07.012 
Figures

(a)

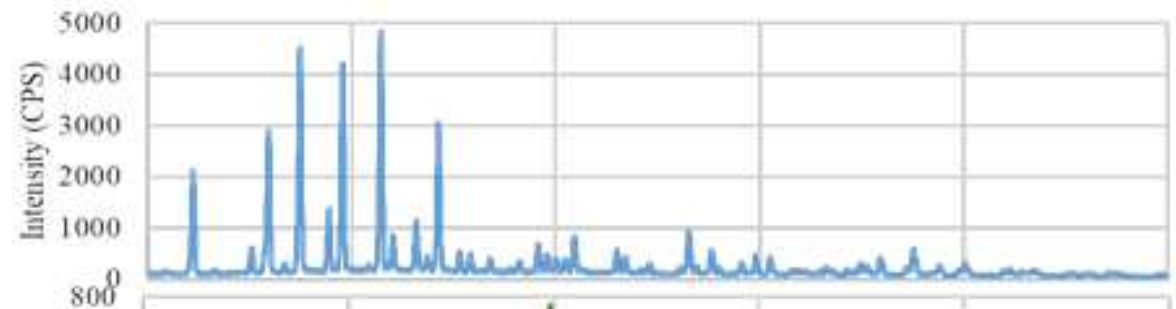

(b)

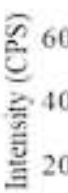

(c)

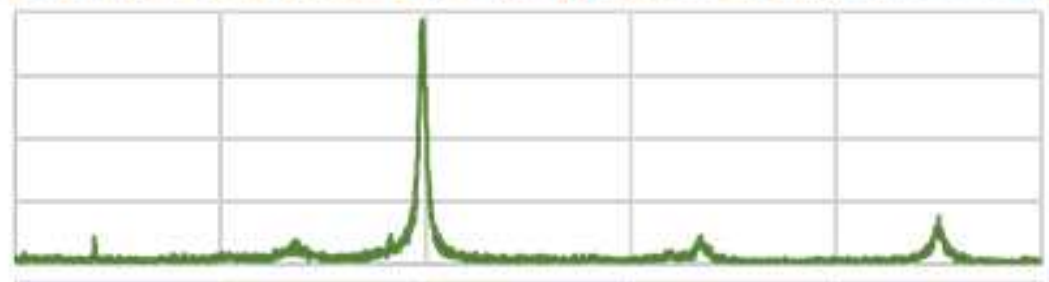

(d)

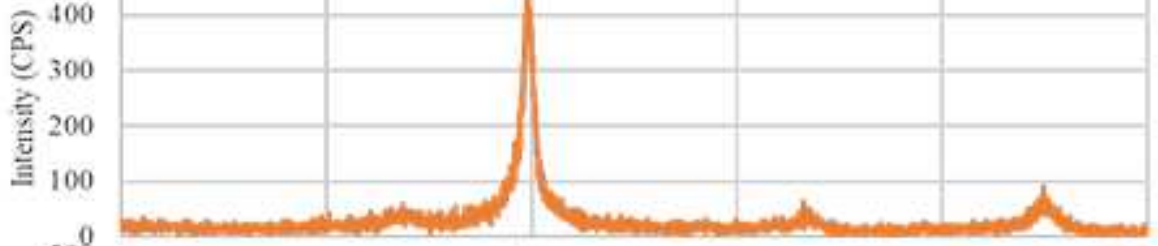

(e)
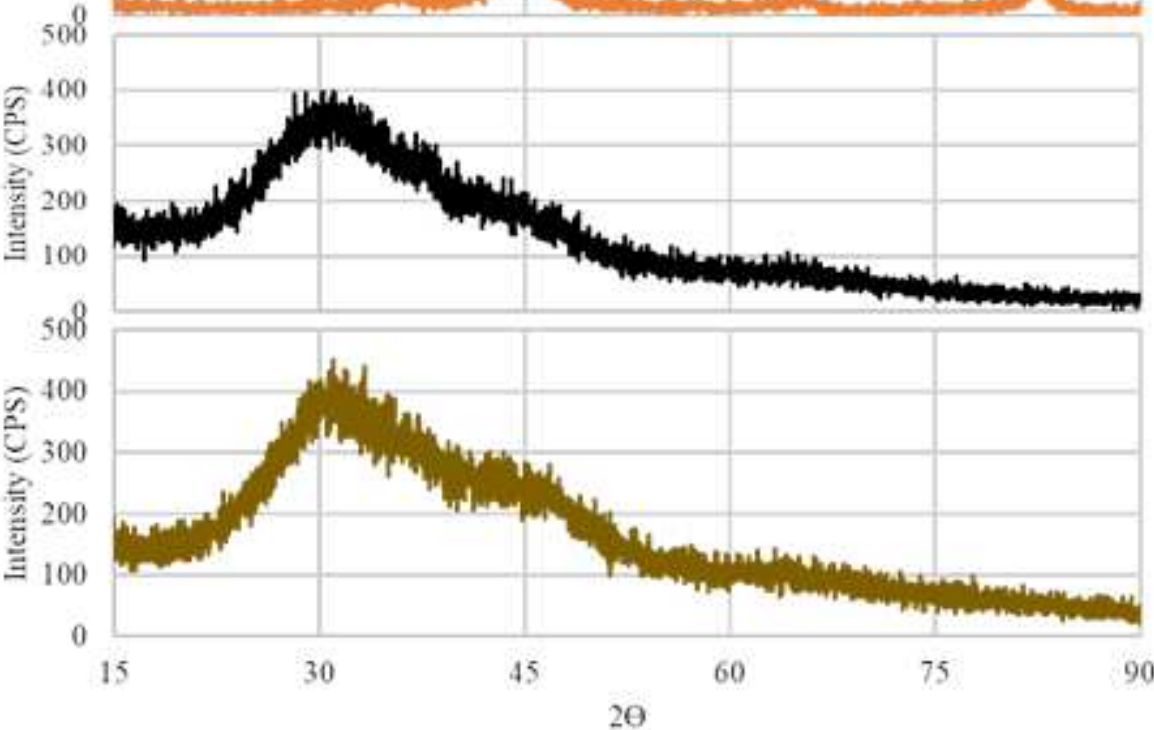

Figure 1

XRD patterns of (a) zeolite, (b) nZVI, (c) nFe/Cu composite (d) nZVI-Z composite (e) nFe/Cu-Z composite. 

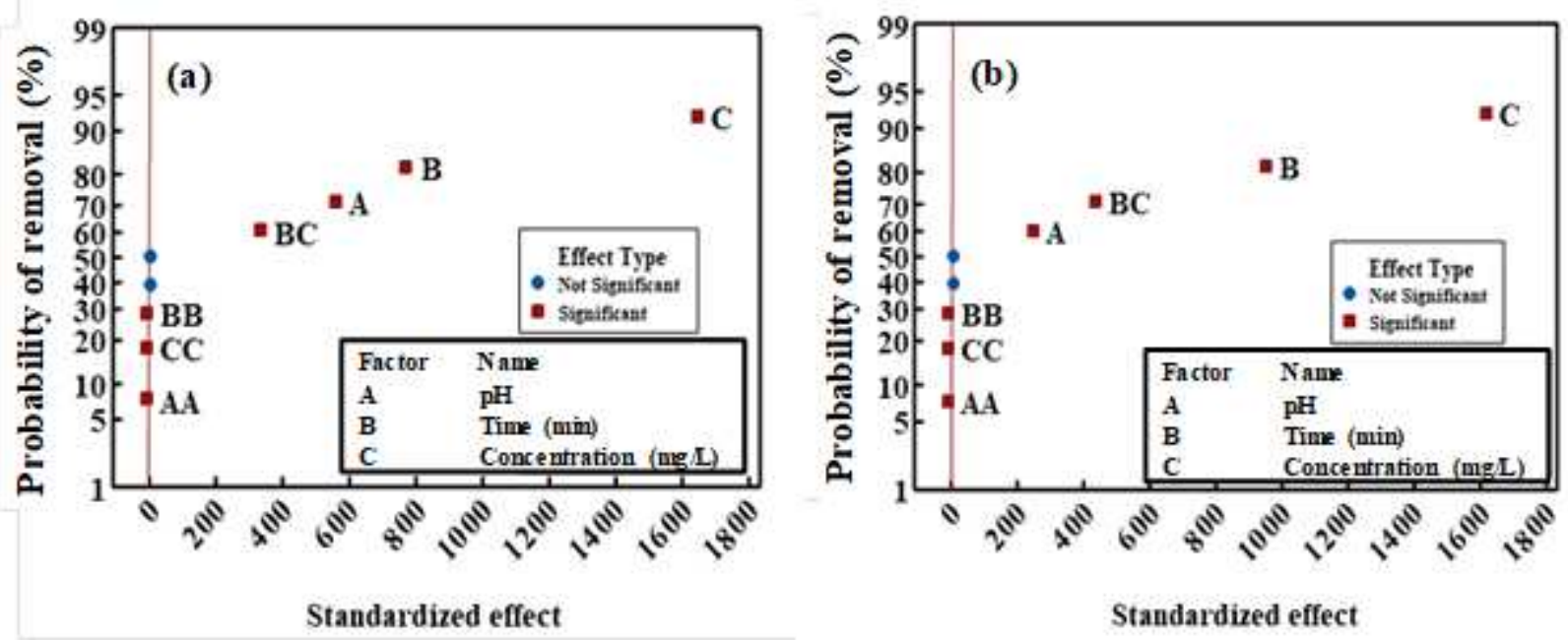

Figure 2

Probability graph for (a) nZVI-Z and (b) $n F e / C u-Z$ adsorbent $(a=5 \%)$. 

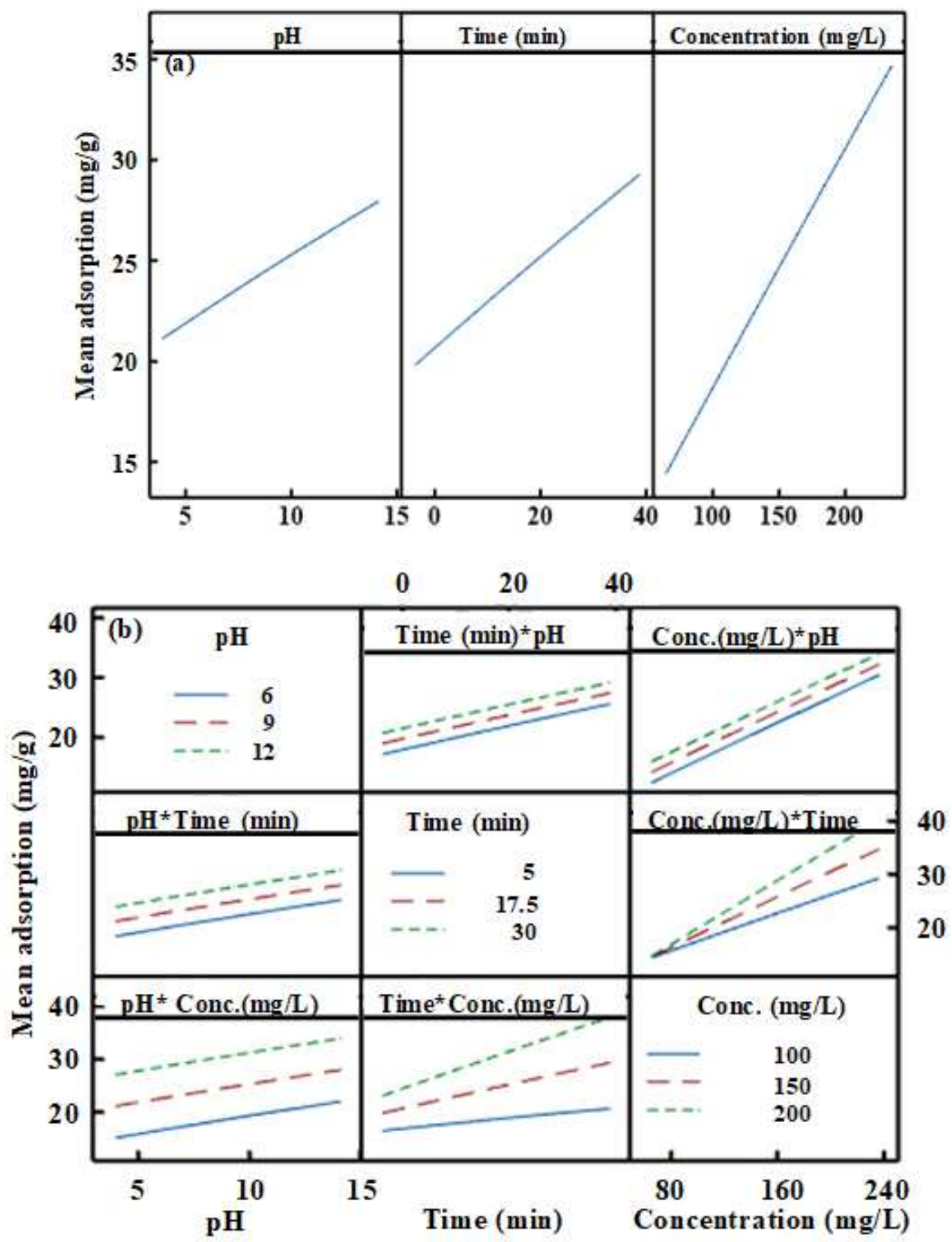

Figure 3

(a). Main and (b) interaction effect graph for the nZVI-Z ( $a=5 \%$ ). 

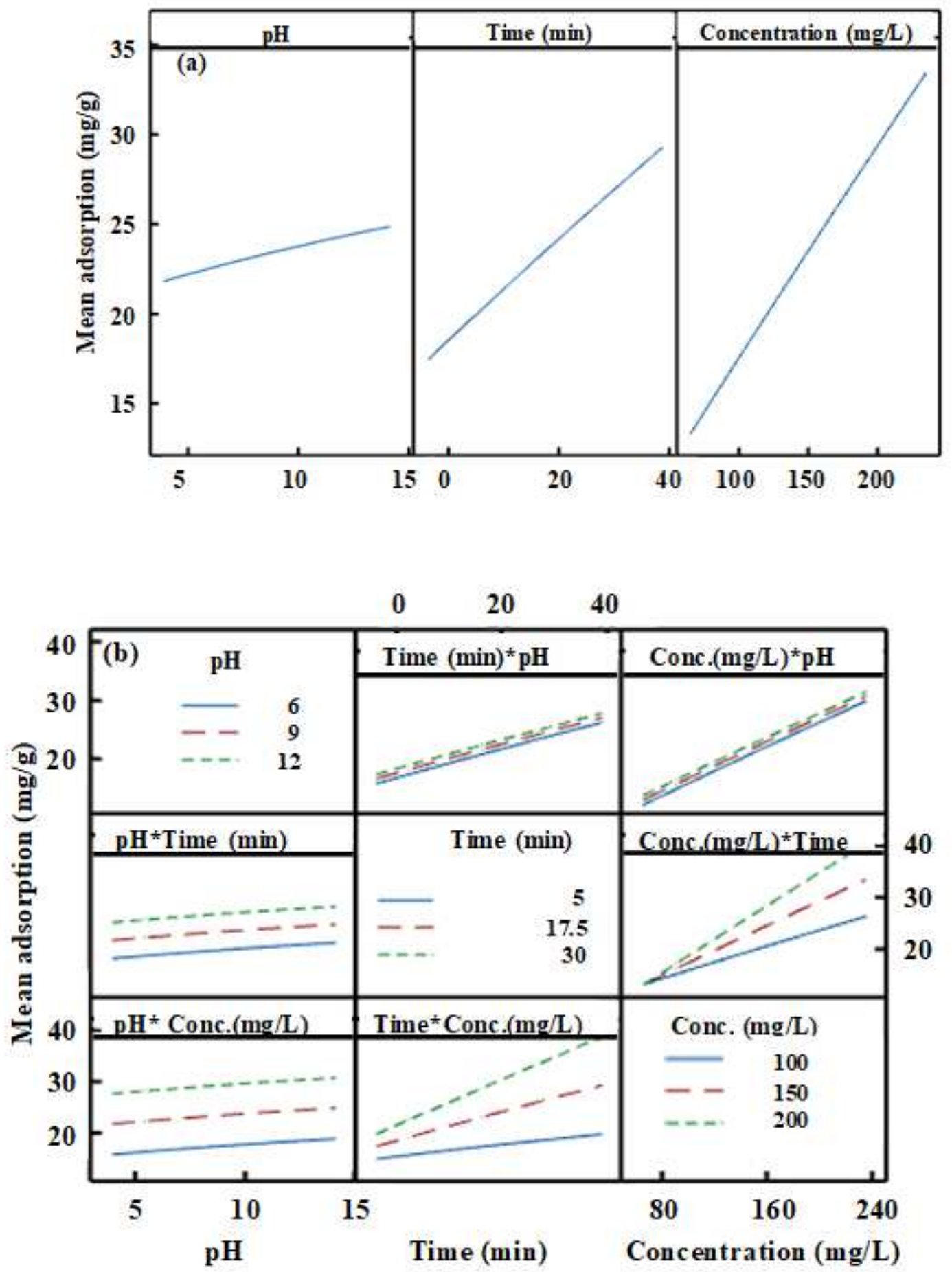

Figure 4

(a). Main and (b) interaction effect graph for the $n F e / C u-Z(a=5 \%)$. 

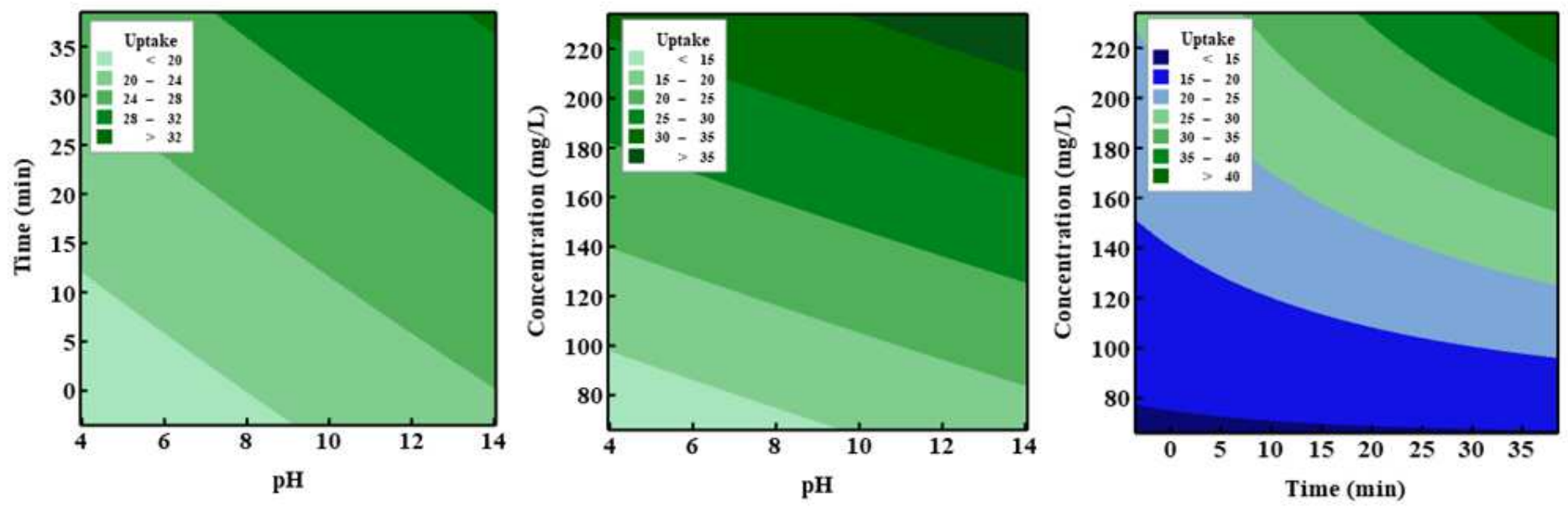

Figure 5

Contour graph of strontium removal for the $\mathrm{nZVI-Z}(a=0.05)$ [Hold values: Concentration $150(\mathrm{mg} / \mathrm{L})$, time $17.5(\mathrm{~min})$ and $\mathrm{pH}$ 9, respectively].
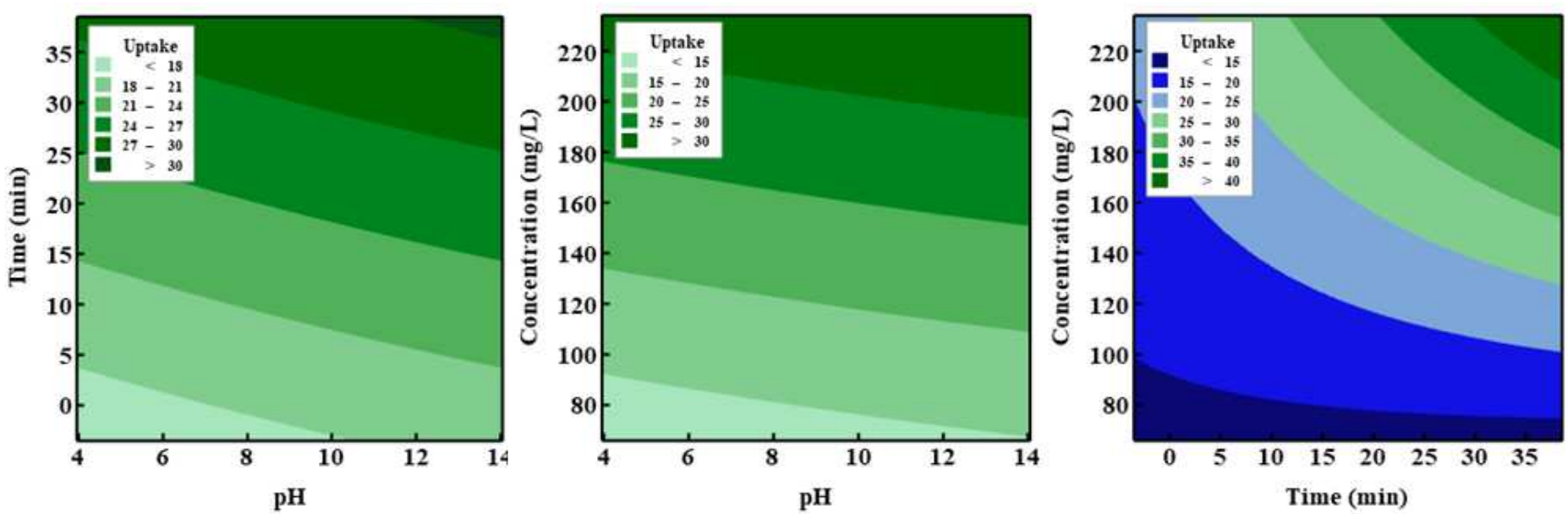

Figure 6

Contour graph of strontium removal for the $\mathrm{nFe} / \mathrm{Cu}-\mathrm{Z}(\mathrm{a}=5 \%)$ [Hold values: Concentration $150(\mathrm{mg} / \mathrm{L})$, time $17.5(\mathrm{~min})$ and $\mathrm{pH}$ 9, respectively] 

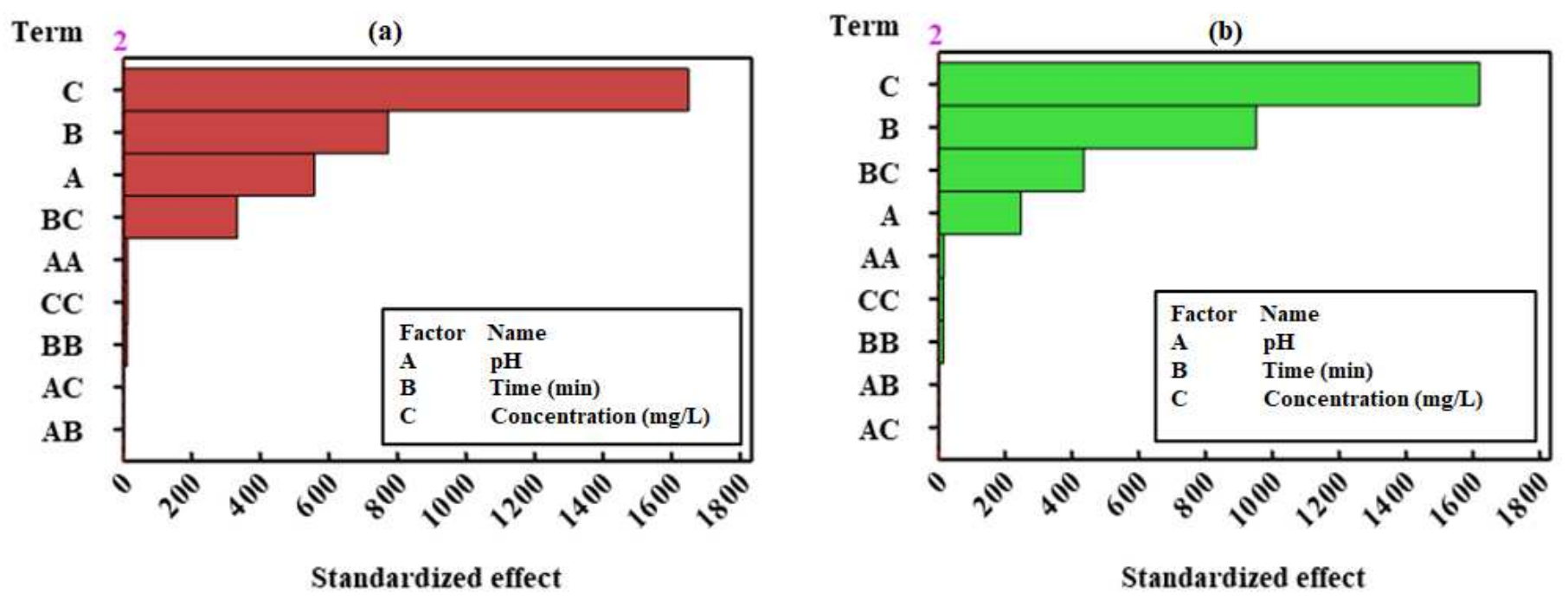

\section{Figure 7}

Pareto chart of strontium removal for $a) n Z V I-Z$ and ii) nFe/Cu-Z adsorbent ( $a=5 \%$ ).
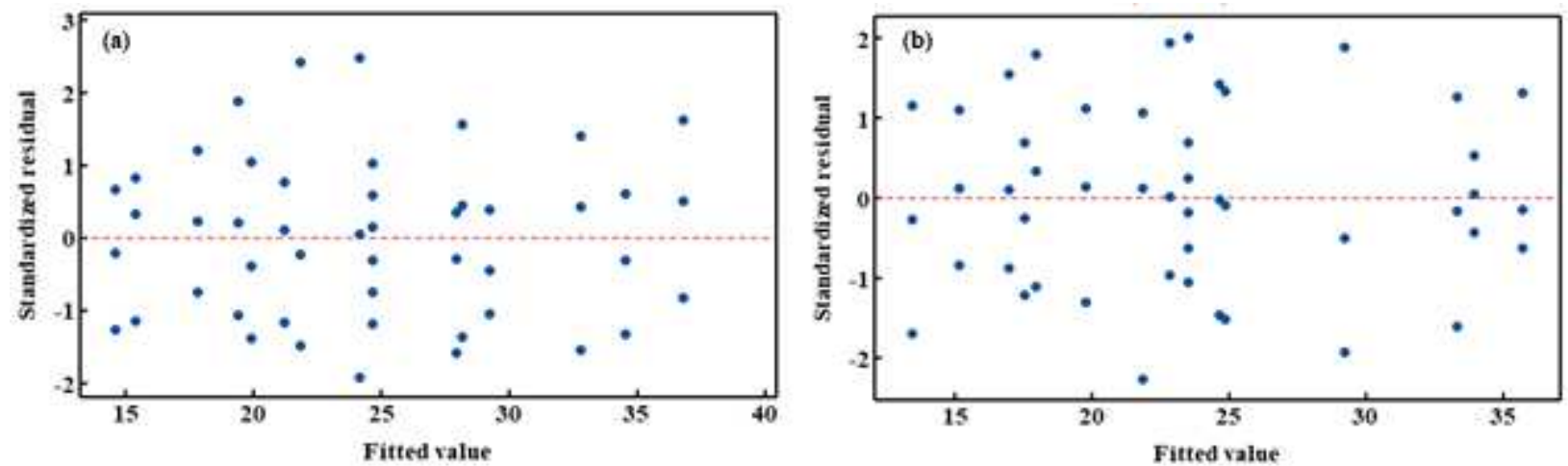

Figure 8

Residual vs. Fits plots of strontium removal for a) nZVI-Z and ii) nFe/Cu-Z adsorbent.
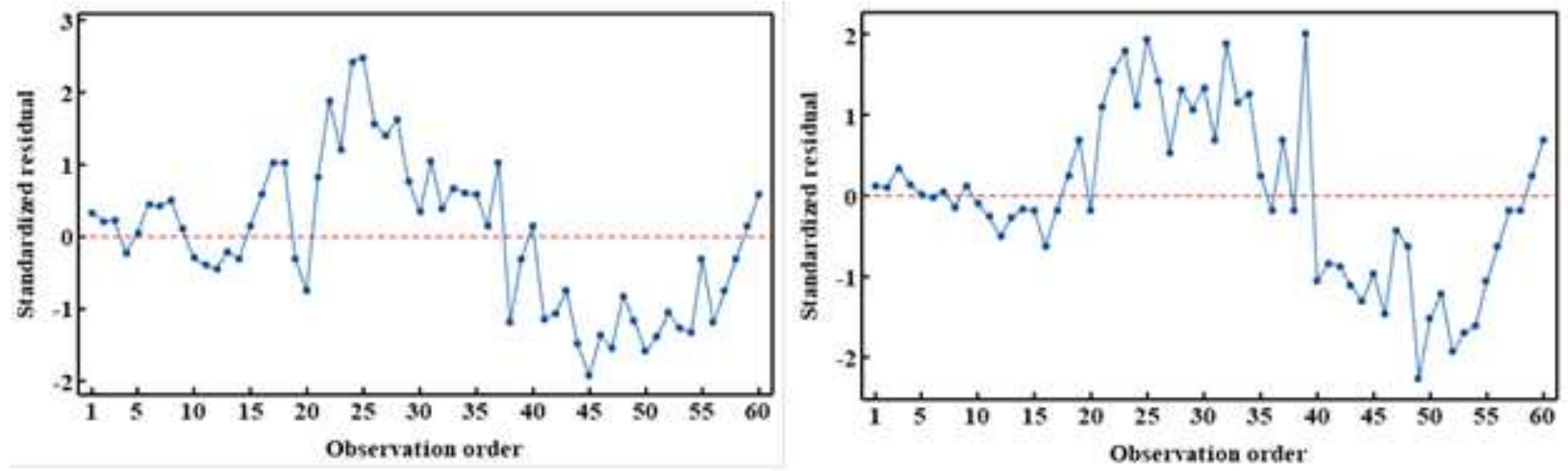

Figure 9

Residual vs. order plots of strontium removal for a) $\mathrm{nZVI-Z}$ and ii) $\mathrm{nFe} / \mathrm{Cu}-\mathrm{Z}$ adsorbent. 

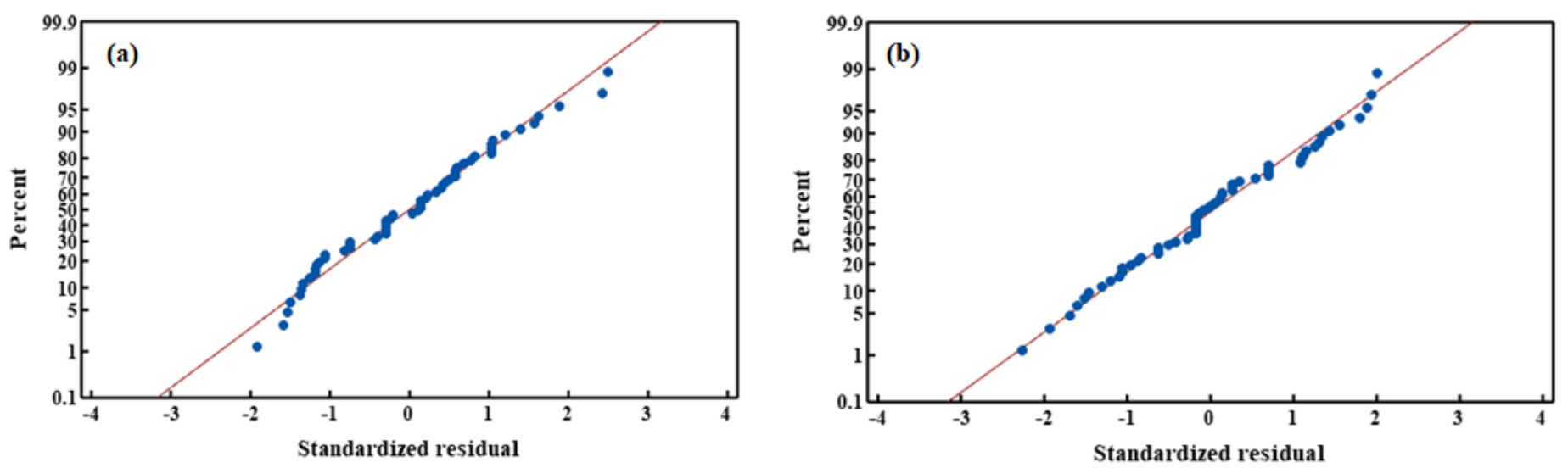

Figure 10

Normal plots of residuals for a) $n Z \mathrm{VI}-\mathrm{Z}$ and ii) $\mathrm{nFe} / \mathrm{Cu}-\mathrm{Z}$ adsorbent $(a=5 \%)$. 
(a)

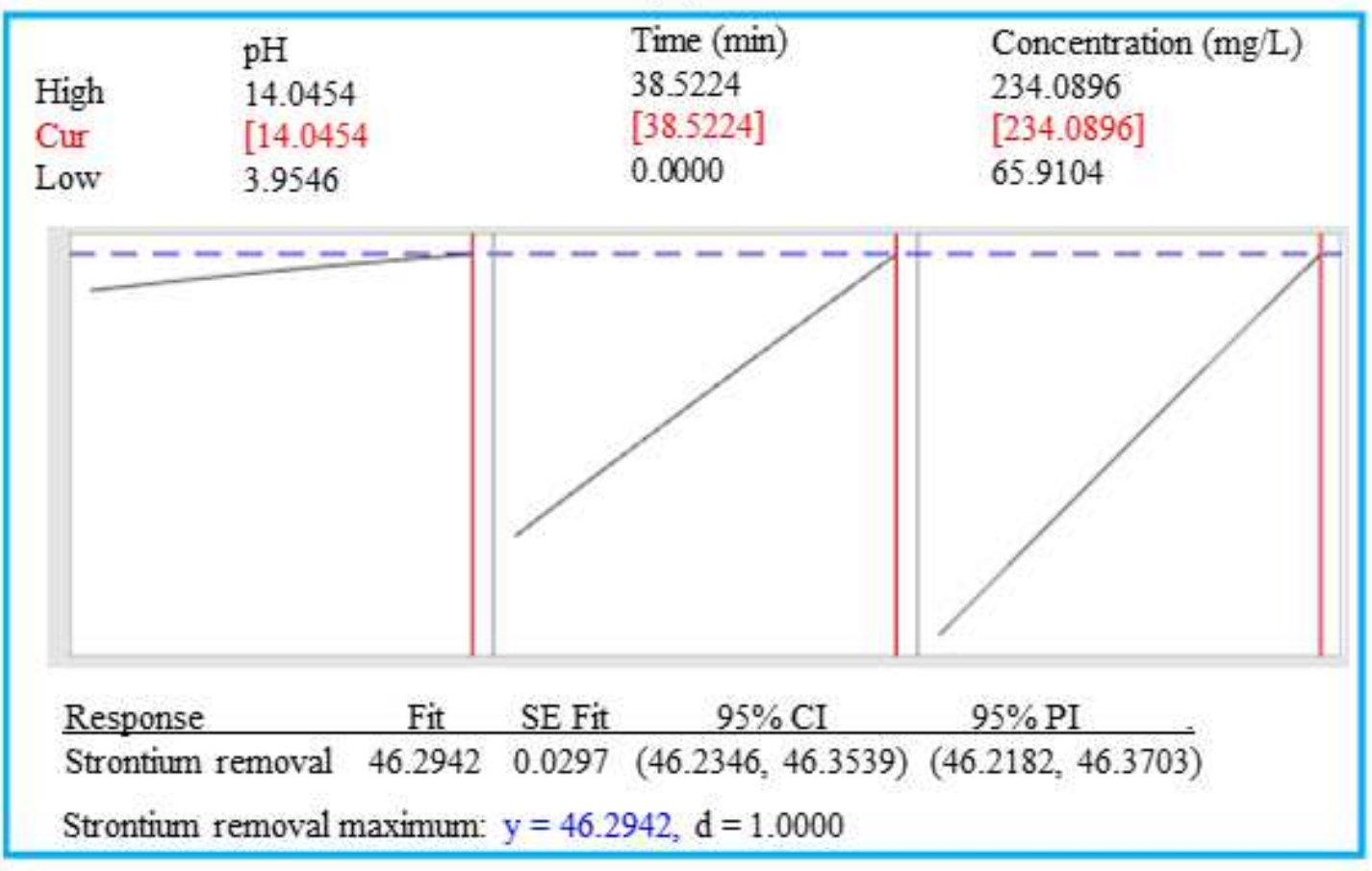

(b)

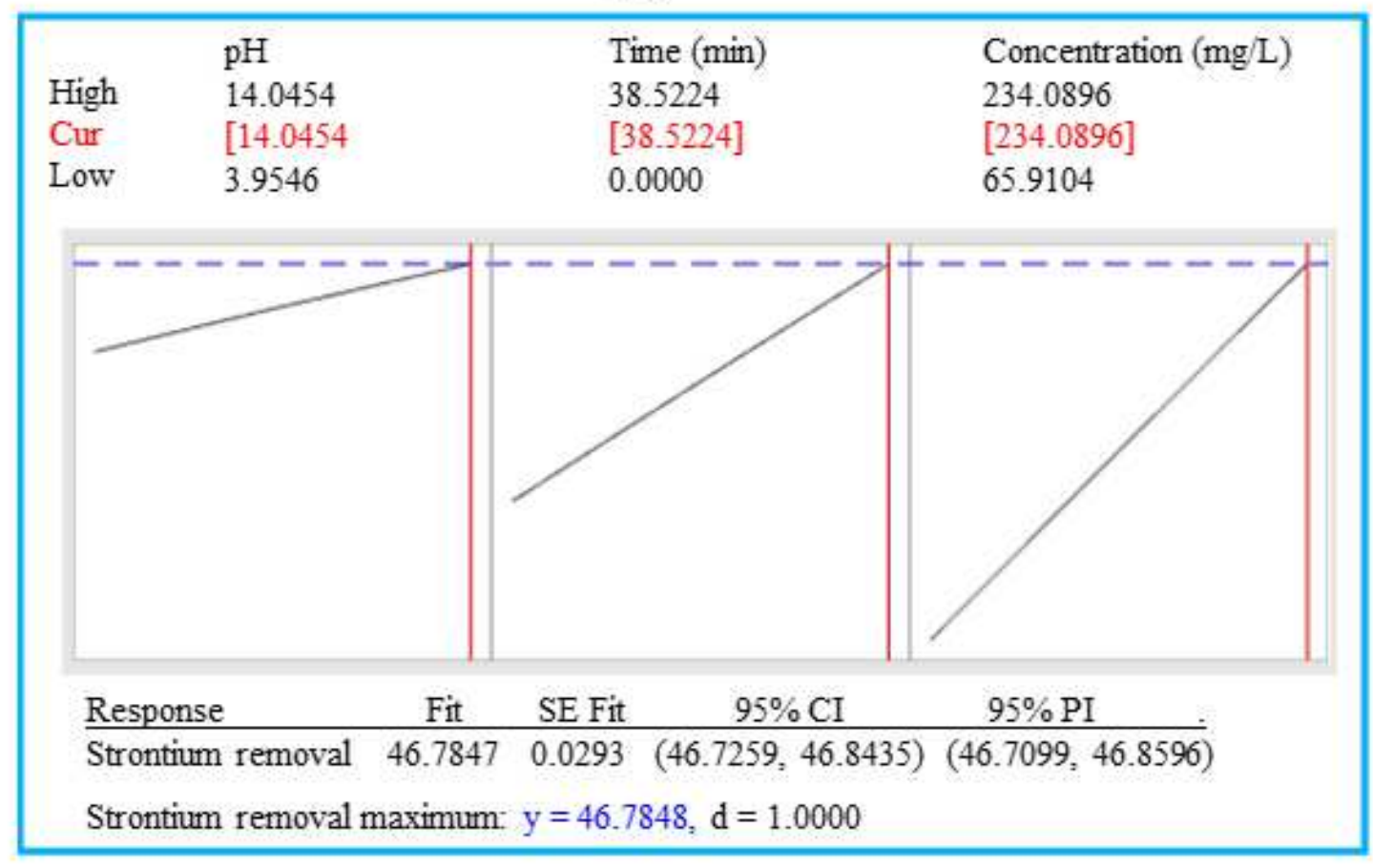

\section{Figure 11}

Response optimization plots of strontium removal for a) nZVI-Z and b) nFe/Cu-Z adsorbent ( $a=5 \%$ ). 

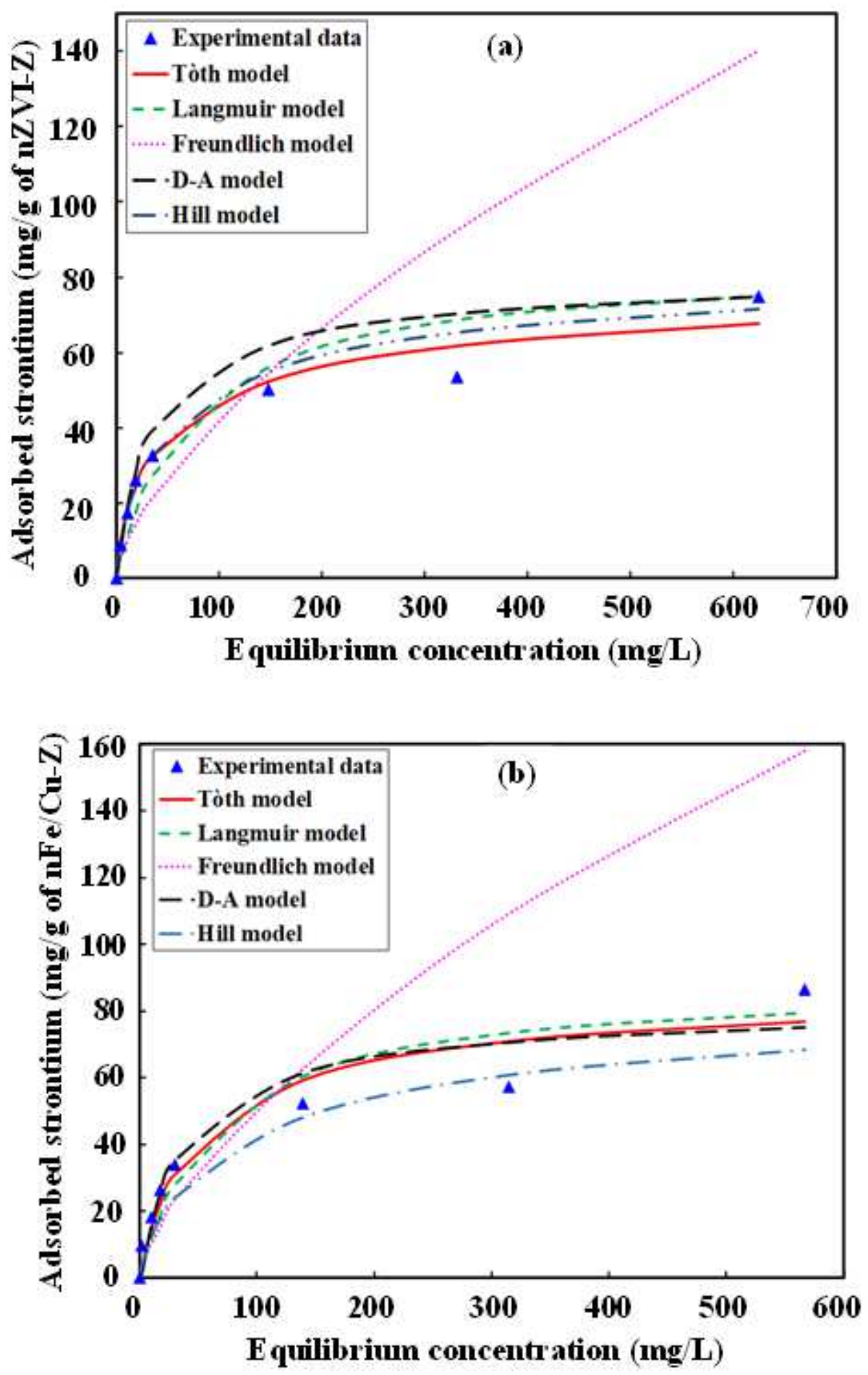

Figure 12

Sorption isotherm of models onto (a) $\mathrm{nZVI-Z}$ and (b) $\mathrm{nFe} / \mathrm{Cu}-\mathrm{Z}$ using RMSD. Fixed parameter: dosage $=5$ $\mathrm{gL}-1, \mathrm{pH}=6$ and temperature $=298 \mathrm{~K})$. 